\title{
An Improved Sub-component Fatigue Testing Method for Material Characterization
}

\author{
Belloni, Federico; Eder, Martin Alexander; Cherrier, B.
}

Published in:

Experimental Techniques

Link to article, DOI:

10.1007/s40799-018-0264-z

Publication date:

2018

Document Version

Publisher's PDF, also known as Version of record

Link back to DTU Orbit

Citation (APA):

Belloni, F., Eder, M. A., \& Cherrier, B. (2018). An Improved Sub-component Fatigue Testing Method for Material Characterization. Experimental Techniques, 42(5), 533-550. https://doi.org/10.1007/s40799-018-0264-z

\section{General rights}

Copyright and moral rights for the publications made accessible in the public portal are retained by the authors and/or other copyright owners and it is a condition of accessing publications that users recognise and abide by the legal requirements associated with these rights.

- Users may download and print one copy of any publication from the public portal for the purpose of private study or research.

- You may not further distribute the material or use it for any profit-making activity or commercial gain

- You may freely distribute the URL identifying the publication in the public portal

If you believe that this document breaches copyright please contact us providing details, and we will remove access to the work immediately and investigate your claim. 


\title{
An Improved Sub-component Fatigue Testing Method for Material Characterization
}

\author{
F. Belloni ${ }^{1}$ (D) M.A. Eder ${ }^{1}$ - B. Cherrier ${ }^{2}$ \\ Received: 2 August 2017 / Accepted: 14 June 2018 / Published online: 3 July 2018 \\ (C) The Society for Experimental Mechanics, Inc 2018
}

\begin{abstract}
In this paper an improved sub-component fatigue testing method is proposed, in which structural optimization is used to obtain specimens in which fatigue failure is precipitated in the designated area away from the boundaries, i.e., load application and fixture points. This is achieved by optimizing the nonlinear beam taper and the dynamic excitation. The major requirement for accurate material characterization through sub-component tests concerns unbiased stress states in the gauge section. However, empiricism shows that many sub-component high-cycle fatigue testing methods suffer from failure in the boundaries rather than the gauge section, which causes bias. The common practice for reinforcing those regions only shifts the issue into new areas of local discontinuities where failure is still caused remotely from the gauge section. An experimental proof of concept demonstrates that optimization of the beam taper can be used to obtain unbiased fatigue test data.
\end{abstract}

Keywords High-cycle fatigue $\cdot$ Sub-component testing $\cdot$ Structural optimization · Dynamic excitation · Fatigue failure

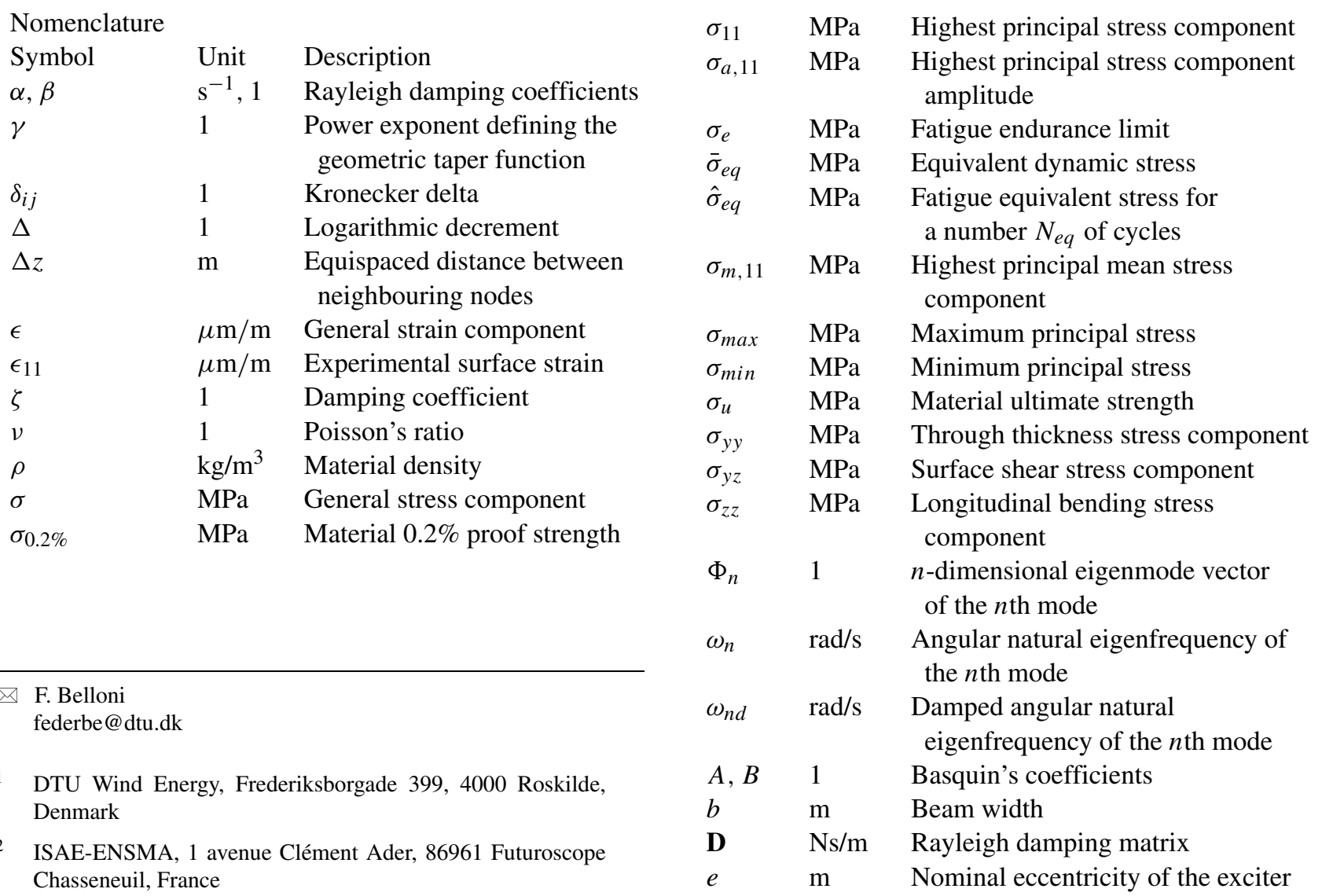




\begin{tabular}{|c|c|c|}
\hline E & MPa & Young's modulus \\
\hline$f_{1}$ & $\mathrm{~Hz}$ & Excitation frequency \\
\hline$f_{2}, f_{3}$ & $\mathrm{~Hz}$ & Second and third eigenfrequencies \\
\hline$f_{\text {lim }}$ & $\mathrm{Hz}$ & Excitation frequency upper limit \\
\hline f & $\mathrm{N}$ & Excitation force amplitude vector \\
\hline$g$ & $\mathrm{~m} / \mathrm{s}^{2}$ & Gravitational constant \\
\hline$h_{0}$ & $\mathrm{~m}$ & Root height at $\mathrm{z}=0$ \\
\hline$h_{L}$ & $\mathrm{~m}$ & Minimum beam tip height at $\mathrm{z}=\mathrm{L}$ \\
\hline$h_{t i p}$ & $\mathrm{~m}$ & Beam height at node $n$ \\
\hline$i, j$ & 1 & $\begin{array}{l}\text { Node number indices } \mathrm{i}=1,2,3, \ldots \mathrm{n} \\
\text { and } \mathrm{j}=1,2,3, \ldots \mathrm{n}\end{array}$ \\
\hline$I$ & $\mathrm{~m}^{4}$ & Second moment of area \\
\hline$k$ & 1 & Temporal index \\
\hline $\mathbf{K}$ & $\mathrm{N} / \mathrm{m}$ & Stiffness matrix \\
\hline$L$ & $\mathrm{~m}$ & Beam length \\
\hline$m(z)$ & $\mathrm{kg} / \mathrm{m}$ & Blade mass per unit length \\
\hline$m_{t}$ & $\mathrm{~kg}$ & Tuning mass \\
\hline $\bar{m}_{d}$ & $\mathrm{~kg}$ & Eccentric mass \\
\hline $\mathbf{M}$ & $\mathrm{kg}$ & Total mass matrix \\
\hline$\hat{\mathbf{M}}_{i j}$ & $\mathrm{~kg}$ & Element of base mass matrix \\
\hline$M$ & $\mathrm{Nm}$ & General bending moment \\
\hline$M_{d}$ & $\mathrm{~N} \mathrm{~m}$ & Dynamic bending moment \\
\hline$M_{m}$ & $\mathrm{~N} \mathrm{~m}$ & Mean (static) bending moment \\
\hline$M_{S}$ & $\mathrm{~N} \mathrm{~m}$ & Self-weight induced bending moment \\
\hline$M_{t}$ & $\mathrm{~N} \mathrm{~m}$ & Tuning mass induced bending moment \\
\hline$n$ & 1 & Total number of nodes \\
\hline$N_{0}$ & 1 & $\begin{array}{l}\text { Number of cycles associated to the } \\
90 \% \text { of the ultimate strength in the } \\
\text { Basquin's equation }\end{array}$ \\
\hline$N_{e}$ & 1 & $\begin{array}{l}\text { Number of cycles associated to the } \\
\text { endurance limit in the Basquin's } \\
\text { equation }\end{array}$ \\
\hline$N_{e q}$ & 1 & $\begin{array}{l}\text { Fatigue equivalent number of cycles } \\
\text { to cause failure }\end{array}$ \\
\hline$N_{f}$ & 1 & $\begin{array}{l}\text { Number of cycles at incipient fatigue } \\
\text { failure }\end{array}$ \\
\hline$R$ & - & Fatigue load ratio \\
\hline$s$ & $\mathrm{~m}$ & Variable of integration \\
\hline $\mathbf{S}$ & $\mathrm{m} / \mathrm{N}$ & Compliance matrix \\
\hline $\mathrm{S}_{i j}$ & $\mathrm{~m} / \mathrm{N}$ & Element of compliance matrix \\
\hline $\mathbf{q}$ & - & Design variable vector \\
\hline$Q$ & $\mathrm{~N}$ & Shear force \\
\hline$t$ & $\mathrm{~s}$ & Time variable \\
\hline$X, Z$ & $\mathrm{~m}$ & Auxiliary variables \\
\hline$y$ & $\mathrm{~m}$ & $\begin{array}{l}\text { Deflection coordinate of the beam } \\
\text { neutral axis }\end{array}$ \\
\hline$y_{t i}, y_{t i+1}$ & $\mathrm{~m}$ & $\begin{array}{l}\text { Adjacent turning points (i.e., maxima) } \\
\text { of the measured displacement history }\end{array}$ \\
\hline $\mathbf{y}$ & $\mathrm{m}$ & Nodal displacement vector \\
\hline$z$ & $\mathrm{~m}$ & $\begin{array}{l}\text { Span-wise coordinate starting from } \\
\text { the root }\end{array}$ \\
\hline & m & Fatigue failure longitudinal \\
\hline
\end{tabular}

$$
\begin{array}{lll}
w & 1 & \begin{array}{c}
\text { Random starting variable index used } \\
\text { in the optimization algorithm }
\end{array} \\
w_{\text {var }} & 1 & \begin{array}{l}
\text { Total number of random starting } \\
\text { variables used in the optimization } \\
\text { algorithm }
\end{array}
\end{array}
$$

\section{Introduction}

Structural testing covers a wide range of sizes. The fishbone diagram depicted in Fig. 1 illustrates the ability of tests at different length scales to consider certain effects on the example of wind turbine rotor blade failure. The orange hatched area in Fig. 1 shows that small scale tests ranging in the order of $1 \times 10^{-3} \mathrm{~m}$ to $1 \times 10^{-1} \mathrm{~m}$ are mainly used for material mechanical property characterization. The advantage of small scale tests lies in cost and time efficiency, lending itself to high probabilistic certainty owing to high sample numbers. On the other hand, Fig. 2 shows the limited capability of small scale tests, e.g., coupons, to capture complex multi-axial stress states and their interaction between different parts that are usually present at full scale. The multi-axial stress states used in the aforementioned context are referring to those induced by the geometry on a macro scale rather than those caused by the fibre layup on a micro scale.

Damage evolution of the same material tested on different scales will be different due to the size effect. That is, both lifetime and failure mode can significantly vary between different length scales. It needs to be stressed that the term size effect as used in this paper does not refer to effects caused by self-similar up-scaling in the realm of fracture mechanics [1-3]. Rather, it refers to effects caused by increasing both the size and the complexity of the geometry. Whilst the main focus of the cited studies is to investigate the effect of scaling on strength and stiffness of materials, this works aims at analyzing the effect of more complex stress states, as it is depicted in Fig. 2.

In contrast to small scale tests, full scale tests typically range between $1 \times 10^{1} \mathrm{~m}$ to $1 \times 10^{2} \mathrm{~m}$ and are the most realistic means to investigate the performance of an entire structure (see Fig. 1). Full scale tests, however, are costly and time consuming due to space requirements, handling, instrumentation, operation and data acquisition. As a consequence, only a limited number of full scale tests can usually be conducted, which increases the uncertainty of experimental data.

Sub-component tests on a medium scale ranging between $1 \times 10^{-2} \mathrm{~m}$ to $1 \mathrm{~m}$ are intended to bridge the gap between small and full scale. Sub-component tests are well established in the automotive, aerospace, mechanical [4] and civil engineering [5] industries, where they are usually 


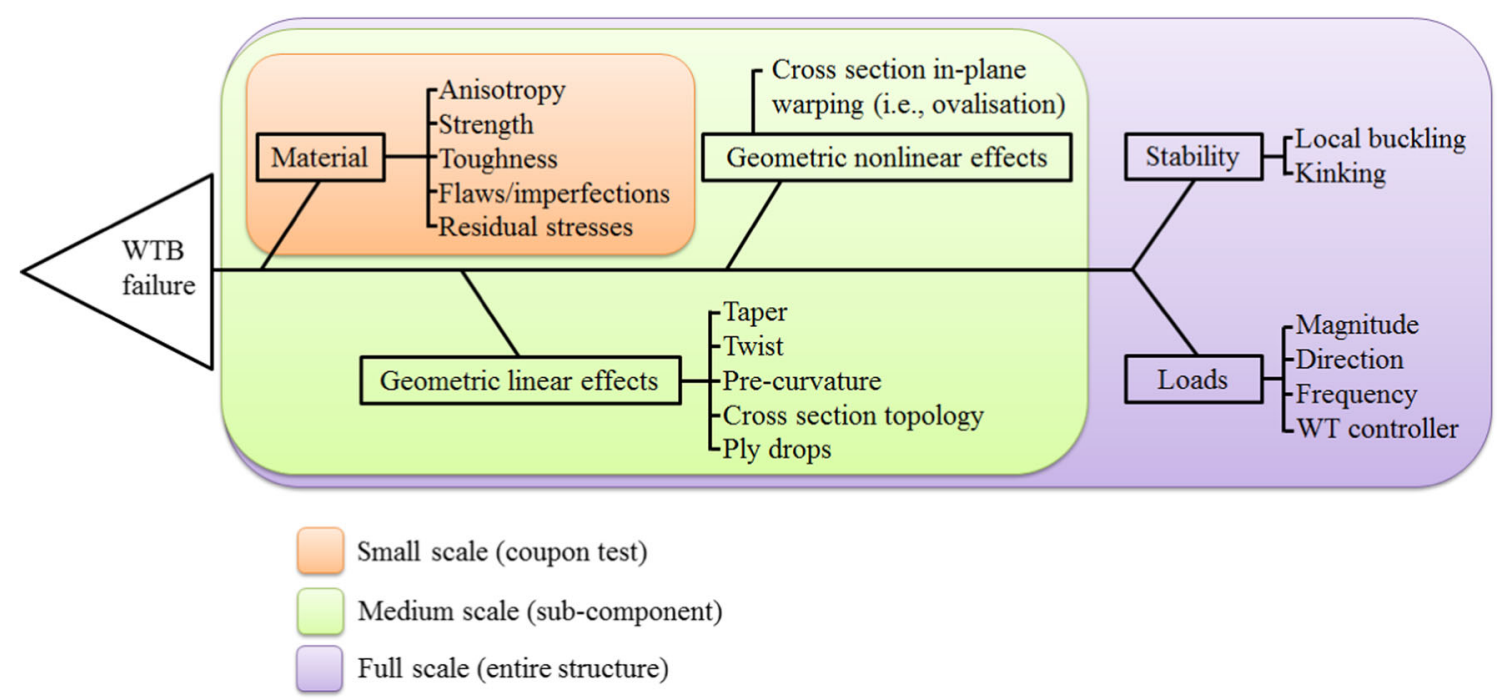

Fig. 1 Fishbone diagram of possible causes of wind turbine blade (WTB) failure, showing the three scale levels of mechanical testing. The classical material classification is shown in orange, the factors influencing the entire structure are held in blue and the aspects captured on sub-component level are shown in green

employed in conjunction with multi-axis pseudo-dynamic loading [6].

A sub-component can be defined as an isolated component or as a part of a full-scale structure where the sub-components themselves may comprise an assembly of several different single components. A sub-component is obtained by separation of the part of interest from the entire structure using a free-body-cut. Figure 3 gives an example of the extraction of a sub-component, the load carrying box girder, from the greater wind turbine blade (WTB) structure. Integral structures such as wind turbine rotor blades are comprised of several adhesively connected multi-material components. The experimental replication of the complex displacement and traction force boundary conditions on the sub-component along its free body cuts renders itself highly challenging [7]. One way to circumvent this issue is to choose a specific representative gauge section in the sub-component and to assign simplified boundary
Fig. 2 Different levels of structural complexity depending on scale: (a) uniform stress distribution in a tensile coupon (b) nonuniform stress distributions with distinct stress gradients in web and flange of a tapered box beam

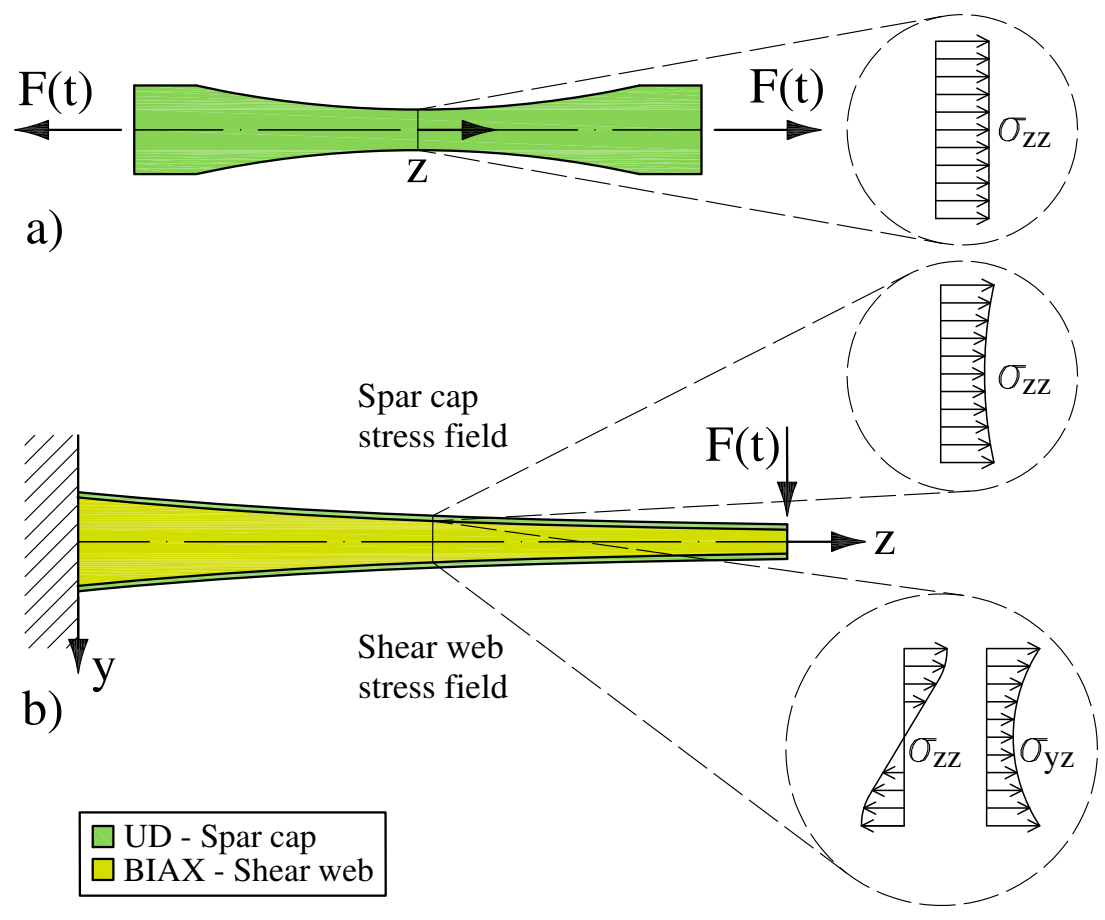


Fig. 3 (a) Large utility wind turbine rotor blade viewed towards the leading edge with indication of load carrying box girder (red) and the lift generating shell (grey) and (b) isolated load carrying box girder consisting of a pair of caps and webs with blade root transition

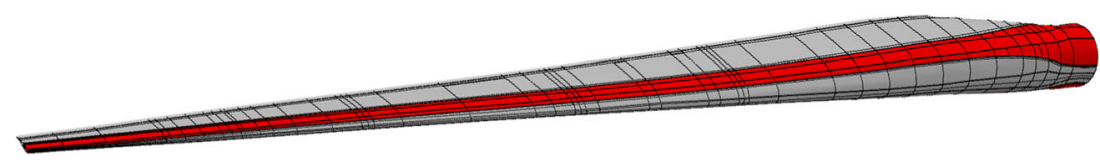

(a)

(b) conditions apart from the gauge section to avoid boundary effect interference. This requires the size of the subcomponent to be long enough to ensure that the decay length of the boundary effects and load introduction points does not reach the gauge section, according to St. Venant's principle.

Mandell et al. [8, 9] conducted four-point bending tests of I-beam sub-components representing the shear web of a wind turbine rotor blade. Adhesive failure and ply drop delaminations were experienced in the load application area, which required repairs during testing and the redesign of the sub-component structural details in order to obtain specimens able to be tested for material characterization purposes. Prismatic composite I-beams were also used by Zarouchas et al. [10] to investigate the mechanical behaviour of adhesive bond lines, resembling the connection between the spar caps and the shear web of a wind turbine blade. In this case wooden reinforcements were deployed to prevent local effects from affecting the test results.

More recently, Asl et al. [11-13] dedicated their work to design composite I-beams and applied structural similitude theory [14] to generate representative down-scaled models of the load carrying part of wind turbine blades. Quasi-static four-point bending was used to experimentally validate this approach on laminated beams with different layups and length scales.

An inherent and well-known drawback of subcomponent testing using the aforementioned approaches, in fact, is failure in the restraints or in the load application points, both of which can lead to biased experimental data. Figure 4(a) depicts a prismatic cantilever type subcomponent subject to a tip load. Such a configuration is prone to fail in the restraint where local stress conditions are strongly at variance with the undisturbed far field stress distribution in the gauge section. Figure 4(b) shows that local reinforcement of restraints and load application points are only shifting the issue. Failure in such cases is usually initiated in the area of local stress concentrations and is caused by high stiffness gradients, e.g., ply-drops, etc., typically at the end of the reinforcement. Furthermore, the adoption of loading platen in a three- or four-point bending test induces contact tractions resulting in local biaxial stress states, all of which alter the desired far field stress distribution.
Sayer et al. [15] addressed this issue by using a linearly tapered beam approach to prevent boundary failure in an adhesively connected glass fibre reinforced composite cantilever sub-component subject to fatigue loading. Fernandez et al. [16] also deployed a linear taper in the design of a C-beam subject to asymmetrical three-point static bending. A not constant flange thickness, maximum at the clamped connection and minimum at the load application point, was adopted to investigate shear failure in bonded joints. However, the flange layup was not designed accordingly to a rigorous mathematical framework.

The proposed method in this paper follows the approach of Sayer et al. [15] and Fernandez et al. [16], where, instead of a constant taper, a shape optimization-based non-constant taper is used as depicted in Fig. 4(c). In this way, failure

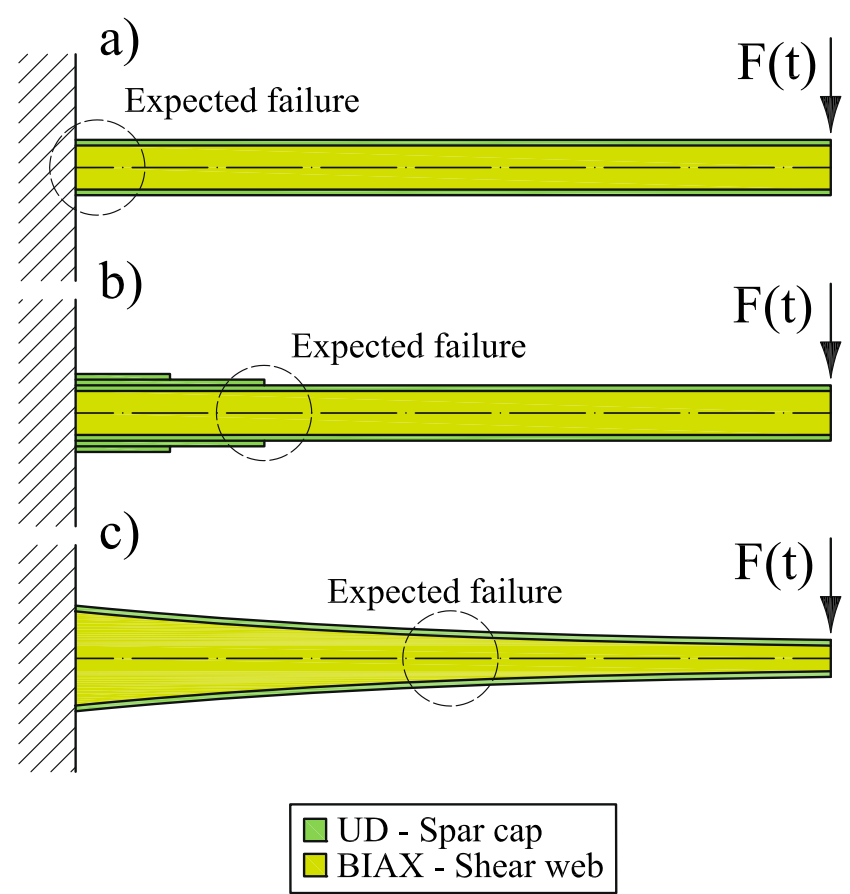

Fig. 4 (a) Prismatic sub-component with warping restrained in the boundary inducing boundary effects, (b) Prismatic sub-component equipped with reinforcement at the clamped connection inducing local stress concentrations affecting the failure mode, (c) Taper optimized sub-component 
can be triggered at a specific beam location, the gauge section, whilst the failure likelihood in the boundaries is substantially reduced.

In this paper, an experimental proof of concept for the proposed method is presented by means of solid tapered aluminium cantilever beams subject to cyclic constant amplitude resonance loading. The optimal taper, mass and excitation parameters were obtained by a numerical shape optimization algorithm that combines the dynamic response of the system with the classic stress-based fatigue life prediction framework. Finite element based dynamic analysis is used to compare and validate the experimental results.

\section{Methodology}

The following section gives a detailed description of the semi-analytical dynamic model used for optimization and the numerical finite element based method used to corroborate the optimization results. The section closes with a description of the experimental methodology used for the proof of concept.

\section{Beam Lumped Mass Model}

The sub-component in the form of a tapered cantilever beam presenting solid rectangular cross section was discretised by a 2D lumped mass model, as shown in Fig. 5. According to the experimental setup described at the end of this section, the model was fully restrained on the left-hand side such that $\left.y\right|_{z=0}=0$ and $\left.\frac{\partial y}{\partial z}\right|_{z=0}=0$. The model consisted of 25 nodes with a single translational degree of freedom per node. The latter was considered sufficient due to the distinct slenderness of the beam rendering rotational inertia negligible. The transverse stiffness of the beam was chosen high enough to avoid spurious dual-axis mode excitation. The lumped mass model formulation neglects geometric nonlinearity, as the deformation levels involved in the highcycle fatigue regime were small compared to the span. Furthermore, damage-induced gradual stiffness degradation was neglected as the sudden death behaviour of the 5083O H111 aluminium alloy used led to catastrophic failure almost immediately after crack initiation [17]. Moreover, the effects of aero-dynamic damping were deemed to be negligible due to a rather small projected surface area.

The dynamic response of the lumped mass model shown in Fig. 5(c) subject to single frequency excitation can be expressed by equation (1).

$\mathbf{M} \ddot{\mathbf{y}}+\mathbf{D} \dot{\mathbf{y}}+\mathbf{K} \mathbf{y}=\mathbf{f} \sin \omega_{d 1} t$

where dot notation was used for temporal derivatives.

The elements of the compliance matrix were computed according to first-order Euler-Bernoulli beam theory. Equation (2) expresses the deformation of node $i$ induced by a unit load applied at node $j$ using the principle of virtual work, as for instance described in [18]. Equation (2) was obtained by numerical integration using the trapezoidal rule [19]. The inverse of the compliance matrix yields the stiffness matrix given by equation (3).

$\mathrm{S}_{i j}=\int_{0}^{z_{i}} \frac{1}{E I(z)}\left(z_{i}-z\right)\left(z_{j}-z\right) \mathrm{d} z$

$\mathbf{K}=\mathbf{S}^{-1}$

The elements of the mass matrix of the beam including tuning and excitation masses can be obtained as follows:

$\hat{\mathbf{M}}_{i j}= \begin{cases}\delta_{i j} \int_{\Delta z(i-1 / 2)}^{\Delta z(i+1 / 2)} m(z) \mathrm{d} z, & \text { if } i<n \\ \delta_{i j}\left(\int_{\Delta z(i-1 / 2)}^{\Delta z(i)} m(z) \mathrm{d} z+m_{t}+\bar{m}_{d}\right), & \text { if } i=n\end{cases}$
Fig. 5 (a) Fatigue test setup showing the resonance exciter and the tuning mass installed at the beam tip, (b) Lumped mass model of the beam with indication of the nodal masses and the sinusoidal force applied at the beam tip, (c) Beam nodal displacements according to the first modal shape $\Phi_{1}$
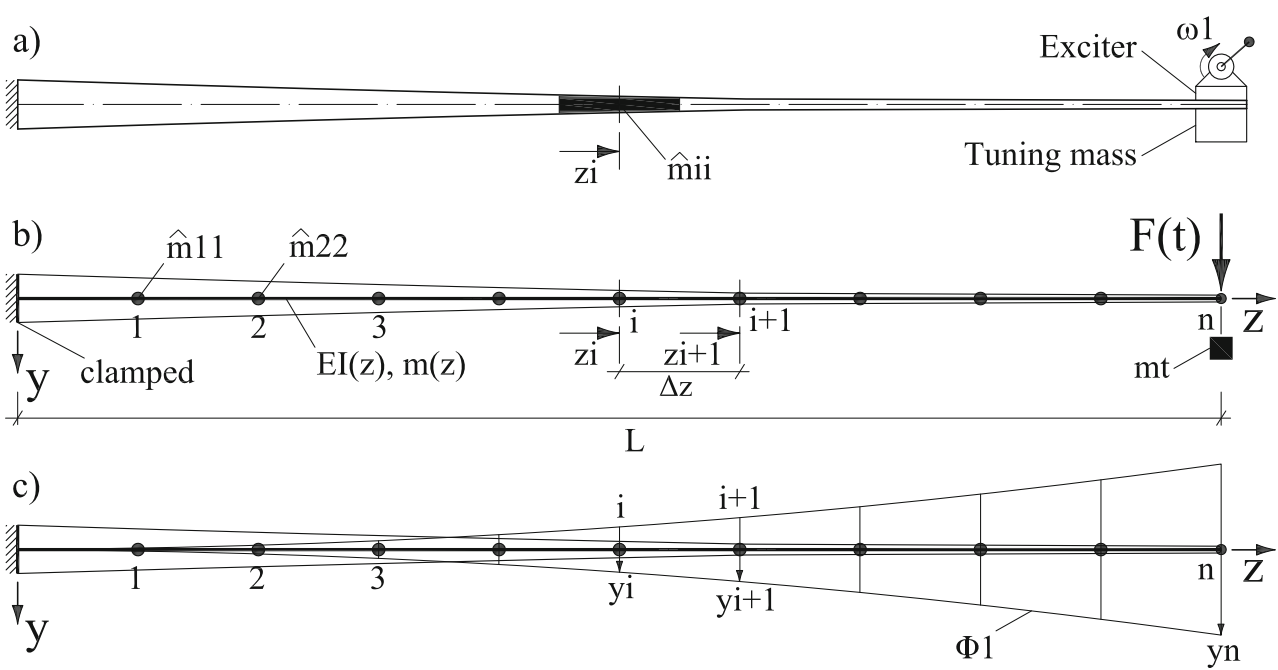
The tuning mass $m_{t}$ installed at the beam tip was entirely assigned to node $n$, together with the excitation mass $\bar{m}_{d}$. Rayleigh damping was used in its most common form, expressed in equation (5), as described by Liu and Gorman [20].

$\mathbf{D}=\alpha \mathbf{M}+\beta \mathbf{K}$

where $\alpha=0 \mathrm{~s}^{-1}$ and $\beta=\frac{2 \zeta}{\omega_{1}}$ were assumed in this work.

By solving the well-known generalised eigenvalue problem posed by equation (6) the corresponding eigenvectors defining the mode shapes were obtained by equation (7)

$$
\begin{aligned}
\left|\mathbf{K}-\omega_{n}^{2} \mathbf{M}\right| & =0 \\
\left(\mathbf{K}-\omega_{n}^{2} \mathbf{M}\right) \Phi_{n} & =0
\end{aligned}
$$

The harmonic force related to the excitation mass centrifugal force presents two components. The component perpendicular to the beam axis, given by equation (8), operating at the first damped eigenfrequency, expressed in equation (9), was applied at the tip node $n$. The other component, parallel to the sub-component longitudinal axis, was instead excluded from the calculation, given its negligible effect on the beam longitudinal stress state.

$F(t)=\bar{m}_{d} e \omega_{d 1}^{2} \sin \left(\omega_{d 1} t\right)$

$\omega_{d 1}=\omega_{1} \sqrt{1-\zeta^{2}}$

The linear second order differential equation given by equation (1) can be decomposed into two sets of linear first order differential equations as follows

$\left\{\begin{array}{l}X_{i k}=y_{i}(t) \\ Z_{i k}=\dot{y}_{i}(t)\end{array}\right.$

$\left\{\begin{array}{l}\dot{X}_{i k}=Z_{i k} ; \\ \dot{Z}_{i k}=\frac{M_{i}}{F_{i k}-Z_{i k} D_{i}-X_{i k} K_{i}} ;\end{array}\right.$

where $M_{i}, D_{i}$ and $K_{i}$ are the nodal modal mass, nodal modal damping and nodal stiffness, respectively. The systems of equations provided in equation (10) and equation (11) can be solved using an explicit numerical solver within Matlab ${ }^{\odot}$ [21]. For the present problem, the Ode15s solver was found to be the most efficient choice for the problem at hand [22]. The nodal bending moment history was computed, according to equation (12), from the second spatial partial derivative of the displacement history obtained from the solution of equation (10), where the displacement partial derivative was numerically evaluated by means of the central difference method [23].

$$
\frac{M(z, t)}{E I(z)}= \begin{cases}\frac{y(z+\Delta z)-2 y(z)+y(z-\Delta z)}{\Delta z^{2}}, & \text { if } 0<z<L \\ \frac{-2 y(z)}{\Delta z^{2}}, & \text { if } z=0 \\ 0, & \text { if } z=L\end{cases}
$$

\section{Stress Calculation in a Tapered Beam}

Under the hypothesis of plane stress conditions in the beam width direction, the tapered geometry evokes all three stress components, as pointed out by Bennati et al. [24]. In the present case, only extreme fibre stress components expressed in global coordinates were of interest. Adopting the reference system shown in Fig. 7(a), the longitudinal bending stress can be obtained with equation (13) according to Navier's equation. In contrast to prismatic beams, the through thickness stress component and the surface shear stress component of tapered beams are other than zero. The through thickness stress component can be obtained by equation (14) as proposed by Bennati et al. [24]. The shear stress component is a strong function of the taper and can be obtained through an extension of the classic Jourawski's formula proposed by Bennati et al., according to equation (15).

$$
\begin{aligned}
\sigma_{z z}(z) & =-\frac{6 M(z)}{b h(z)^{2}} \\
\sigma_{y y}(z) & =\tan ^{2}\left(\frac{1}{2} \frac{\mathrm{d} h(z)}{\mathrm{d} z}\right) \sigma_{z z}(z) \\
\sigma_{y z}(z) & =\frac{M(z) h(z)}{8 I(z)} \frac{\mathrm{d} h(z)}{\mathrm{d} z}
\end{aligned}
$$

The highest principal stress $\sigma_{11}(z)$ can be consequently calculated with the three stress components by equation (16).

$\sigma_{11}(z)=\frac{\sigma_{z z}(z)+\sigma_{y y}(z)}{2}+\sqrt{\left(\frac{\sigma_{z z}(z)-\sigma_{y y}(z)}{2}\right)^{2}+\sigma_{y z}(z)^{2}}$

Equation (16) was used to evaluate the principal mean stress $\sigma_{m, 11}(z)$ and the principal stress amplitude $\sigma_{a, 11}(z)$, which were converted to equivalent dynamic stress by means of a symmetric constant life diagram (CLD), qualitatively presented in Fig. 6, and defined by equation (17).

$\bar{\sigma}_{e q}(z)=\frac{\sigma_{u} \sigma_{a, 11}(z)}{\sigma_{u}-\sigma_{m, 11}(z)}$

\section{Static Section Forces and Fatigue Strength}

The static bending moment distribution in the lumped mass model induced by the self-weight of the beam was obtained with a two-step procedure. First, the shear force was computed by equation (18) using the boundary condition $\left.Q\right|_{z=L}=0$ at the tip to determine the integration constant:

$Q(z)=\left.Q\right|_{z=L}+g \int_{L}^{z} m(s) \mathrm{d} s$ 
Fig. 6 Simplified symmetric constant life diagram used to convert stress amplitude and mean stress into an equivalent stress amplitude at $R=-1$

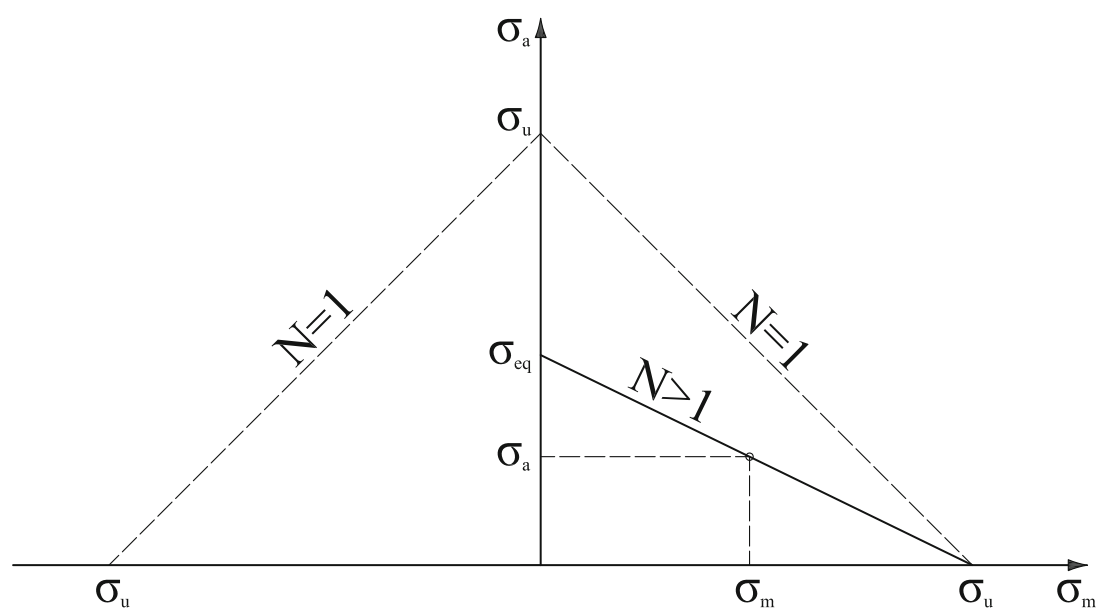

Secondly, the bending moment distribution was obtained using equation (19) with the boundary condition $\left.M_{s}\right|_{z=L}=0$ :

$M_{s}(z)=\left.M_{s}\right|_{z=L}+g \int_{L}^{z} Q(s) \mathrm{d} s$

The static bending moment distribution induced by the selfweight of the external mass applied at the beam tip can be obtained by equation (20). Using the superposition principle, the resulting static bending moment can eventually be obtained by equation (21).

$M_{t}(z)=-g m_{t}(L-z)$

$M_{m}(z)=M_{S}(z)+M_{t}(z)$

The fatigue strength was calculated according to the Basquin's approach [25], given by equation (22) for an equivalent number of cycles $N_{e q}$.

$\hat{\sigma}_{e q}=A N_{e q}^{B}$

where the coefficients $A$ and $B$ can be obtained using equation (23).

$\left\{\begin{array}{l}A=\frac{\sigma_{e}}{N_{e}^{B}} ; \\ B=\frac{\log _{10}\left(\sigma_{e}\right)-\log _{10}\left(0.9 \sigma_{u}\right)}{\log _{10}\left(N_{e}\right)-\log _{10}\left(N_{0}\right)} ;\end{array}\right.$

\section{Optimization Algorithm}

A numerical optimization algorithm was employed in order to find an optimum solution for the beam geometry and the dynamic excitation, where fatigue failure is triggered at the beam mid-span. The components of the continuous optimization algorithm are subsequently described. The longitudinal cross section height of the beam is defined by equation (24), which was found to enhance the taper curvature and allowed for the tip height to be constrained to the lower bound $h_{L}$. It needs to be mentioned that the obtained beam tip height $h_{\text {tip }}$ does not coincide with $h_{L}$, as it is depicted in Fig. 7(b).

$h(z)=h_{L}+\left(h_{0}-h_{L}\right) e^{-\gamma z}$

The bending stiffness and mass per unit length used for equations (2), (3) and (4) can be obtained by the following expressions:

$$
\begin{aligned}
E I(z) & =\frac{E b h(z)^{3}}{12} \\
m(z) & =\rho b h(z)
\end{aligned}
$$

The nature of the steady state mono-frequency response does not require time history analysis for the purpose of shape optimization, which therefore was omitted in the optimization algorithm for the sake of computational efficiency.

The so-called tuning mass installed at the beam tip (see Fig. 5(a)) serves three purposes. First, it increases the curvature of the dynamic stress amplitude distribution which assists the optimizer to meet the objective function. Secondly, it can be used to control the sub-component resonance frequency. The ability to control the natural frequency is less important for metals but proves to be crucial in the case of composite materials to delimit adiabatic heating, as studied by Kim and Ebert [26]. Third, the tuning mass can be used to control the R-ratio in the desired gauge section.

After assembly of the stiffness matrix and mass matrix, equation (7) can be solved, where the first normalised eigenvector $\Phi_{1}(z)$ was scaled with the beam tip displacement $y_{n}$ according to equation (27). The nodal dynamic bending moment distribution $M_{d}(z)$ can be subsequently obtained by using equation (27) in equation (12).

$y(z)=y_{n} \Phi_{1}(z)$ 


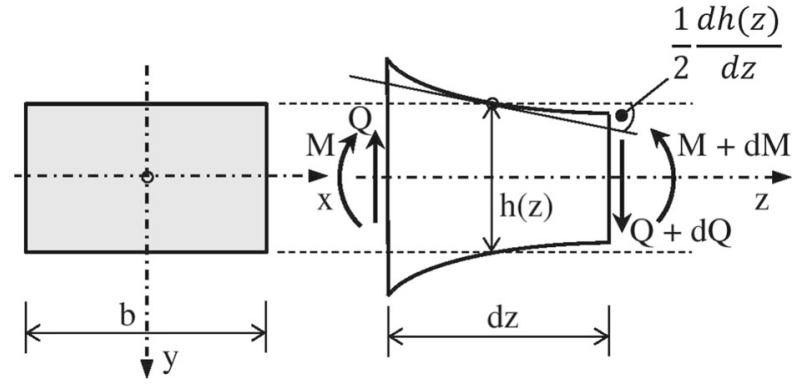

(a)

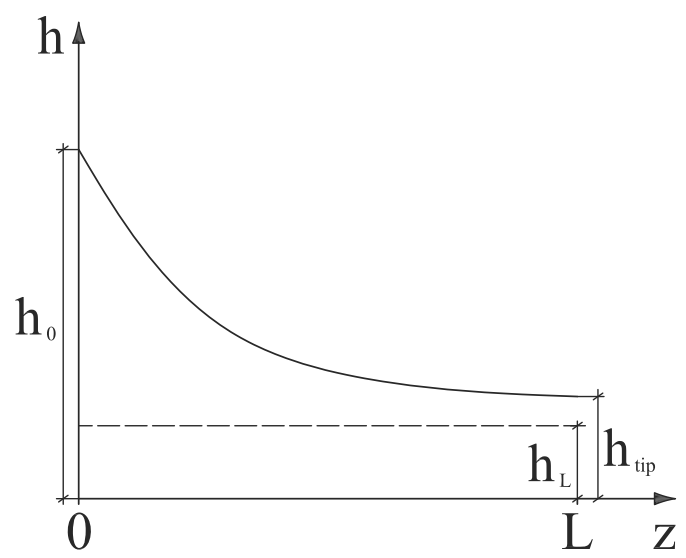

(b)

Fig. 7 (a) Infinitesimal beam element showing the rectangular cross-section force convention and taper parameters used to calculate the three stress components and (b) beam height as a function of the longitudinal coordinate according to equation (24); the difference between the manufacturing constraint on the minimum beam tip height $h_{L}$ and the optimized tip height $h_{\text {tip }}$ is indicated

The optimization problem is posed by finding the optimal solution for four different parameters which are held by the design variable vector which can be written as follows.

$\mathbf{q}=\left(\begin{array}{llll}h_{0} & \gamma & m_{t} & y_{n}\end{array}\right)$

The objective function was defined as the absolute difference between the fatigue strength and the dynamic extreme fibre stress amplitude at the beam mid-span. The optimization problem given by equation (29) is continuous and can be solved using a gradient descent based approach. For this purpose, the readily available Matlab optimiser fmincon [21] was used for linearly constrained optimization. By default, fmincon computes the sensitivities, i.e., the partial differentials of the solution with respect to the design variables, by finite differences. Although these sensitivities were not provided analytically, the finite difference approach is justified by assuming the presence of small finite difference errors due to the semi-analytical formulation of the model. Table 1 summarizes the adopted settings for fmincon. The optimization problem posed above is non-convex, since the optimiser usually converges to the local minima of the solution space in the vicinity of the initial design variables. In order to overcome this issue,

Table 1 Algorithm settings defining the Matlab optimiser fmincon

\begin{tabular}{ll}
\hline Maximum number of function evaluations & $1 \times 10^{5}$ \\
Maximum number of iterations & $1 \times 10^{4}$ \\
Gradients of the objective function provided & No \\
Gradients of the constraints provided & No \\
Optimization algorithm & Interior-point (default)
\end{tabular}

the optimization procedure was repeated for $w_{v a r}=100$ randomly selected starting variables.

$$
\begin{array}{cl}
\underset{\mathbf{q}}{\operatorname{minimize}} & f(\mathbf{q}, y(\mathbf{q}))=\left.\left|\bar{\sigma}_{e q}(\mathbf{q}, y(\mathbf{q}))-\hat{\sigma}_{e q}\right|\right|_{z=\frac{L}{2}} \\
\text { subject to } & \omega_{1}(\mathbf{K}(\mathbf{q}), \mathbf{M}(\mathbf{q}))-2 \pi f_{\text {lim }} \leq 0 \\
& 3.0 \times 10^{2} \mathrm{~mm} \leq h_{0} \leq 4.0 \times 10^{2} \mathrm{~mm} \\
& 1.5 \leq \gamma \leq 2.5 \\
& m_{t}-6.0 \mathrm{~kg} \leq 0 \\
& y_{n}-0.125 \mathrm{~L} \leq 0
\end{array}
$$

In the constraint set stipulated in equation (29), the excitation limit frequency $f_{\text {lim }}$ was set to $2.5 \mathrm{~Hz}$. Constraints were set on the beam root height $h_{0}$ and the coefficient $\gamma$ in order to steer the beam taper accentuation. The third constraint was set on the maximum value of the tuning mass $m_{t}$. The last constraint limits the tip deformation to $12.5 \%$ of the span to avoid excessive deviation from first-order beam theory used in equation (2).

The implementation of the optimization algorithm can be described in a pseudo-code as follows.

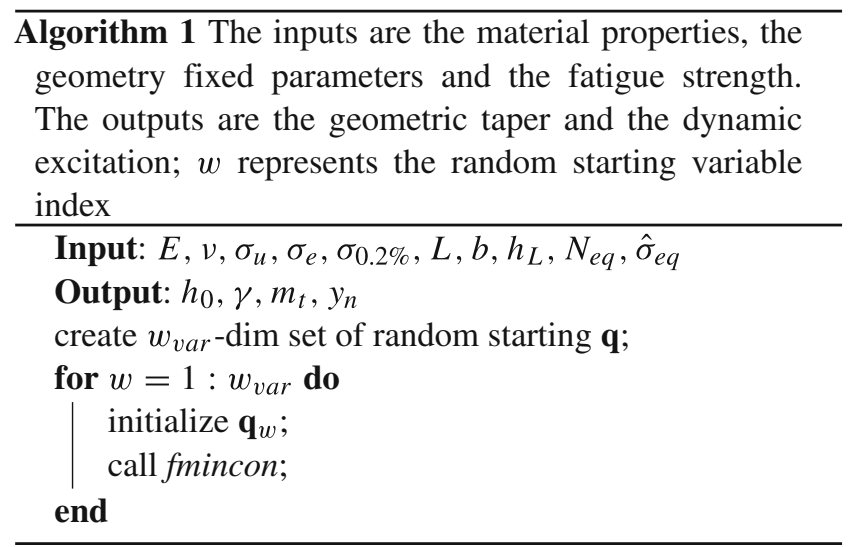


Table 2 Constant parameters not subject to optimization defining the design space

\begin{tabular}{ll}
\hline$L$ & $2000 \mathrm{~mm}$ \\
$b$ & $40 \mathrm{~mm}$ \\
$h_{L}$ & $10 \mathrm{~mm}$ \\
$N_{e q}$ & $4 \times 10^{5}$ \\
\hline
\end{tabular}

\section{Numerical Model Validation}

The sub-component beam was modelled within the commercial finite element software package Abaqus ${ }^{\odot}$ [27]. The numerical model was used to validate the semi-analytical model in terms of eigenfrequencies, eigenmodes, deflections, stresses and strains. The geometry and material parameters are given in Tables 2 and 3, respectively. The values in Table 2 represent the parameters that defined the design space for the beam geometry. Vickers hardness (HV) was verified on a polished surface of a sample with a Struers DuraScan tester along one line at a distance of $1 \mathrm{~mm}$. For each line 10 individual measurements were performed using a load of $3 \mathrm{~kg}$ and a dwell time of $15 \mathrm{~s}$.

The beam root was fully fixed using a kinematic coupling constraint with a master node, whose three degrees of freedom were restrained according to $u_{x}=u_{y}=u_{r z}=$ 0 . Similarly, all nodes of the beam end cross section were coupled to a tip master node. The beam self-weight and the tip tuning mass were applied using a quasi-static solution strategy. A concentrated sinusoidal force expressed by equation (8) was subsequently applied at the tip master node. It is noteworthy that the tuning mass and the eccentric mass employed for the model validation were equal to $2.0 \mathrm{~kg}$ and $25 \mathrm{~g}$, respectively. The chosen mass values were lower than the values used during the fatigue test conducted to failure to avoid plastic deformation by preserving the linear-elastic material response for validation purposes.

The sub-component was discretized with 4004 -node bilinear plane stress quadrilateral elements with incompatible modes $\left(\right.$ Abaqus $^{\odot}$ element type CPS4I). The adopted elements had a constant length of $10 \mathrm{~mm}$ and a height range between $4.18 \mathrm{~mm}$ at the root and $1.33 \mathrm{~mm}$ at the tip. Figure 8

Table 3 Mechanical properties of 5083-O H111 aluminium alloy

\begin{tabular}{ll}
\hline$\rho$ & $2650 \mathrm{~kg} / \mathrm{m}^{3}$ \\
$\mathrm{E}$ & $72 \mathrm{GPa}$ \\
$v$ & 0.33 \\
$\sigma_{0.2 \%}$ & $145 \mathrm{MPa}$ \\
$\sigma_{e}$ & $150 \mathrm{MPa}$ \\
$\sigma_{u}$ & $300 \mathrm{MPa}$ \\
Elong. at Break & $23 \%$ \\
Hardness Vickers & $75 \mathrm{HV}$ \\
\hline
\end{tabular}

shows the undeformed beam superimposed with the first mode shape.

The Rayleigh damping formulation as expressed in equation (5) was used. The two damping factors were adopted as follows: $\alpha=0 \mathrm{~s}^{-1}$ and $\beta=\frac{2 \zeta}{\omega_{1}}$ where $\zeta$ was experimentally determined, as explained in Section 2. The regular Newton-Raphson solver technique was used, whilst the implicit Hilber-Hughes-Taylor operator [28] for integration of the equations of motion was selected. The adopted step size for dynamic analysis was $0.005 \mathrm{~s}$, found to be a good compromise value between an acceptable simulation time and solution accuracy.

\section{Sub-component Testing Methodology}

Figure 9(a) shows an elevation of the sub-component whose geometry is defined by the fixed parameters given in Table 2 and the optimised parameters listed in Table 4 (see Section 2). Figure 9(b) shows the as-built geometry, where the root section height at the fixed end was maintained constant for a length of $310 \mathrm{~mm}$ to allow a firm grip connection. The beam was consequently clamped to a rigid frame type test rig between two $10 \mathrm{~mm}$ thick carbon steel plates. The clamping pressure was provided by an array of four snug, tightly pre-stressed M10 bolts located on either side of the root extension. The section height at the tip was extended beyond the nominal length at a constant height for a length of $50 \mathrm{~mm}$ to provide a proper seat for the exciter chassis.

The sub-components were water-cut from a $40 \mathrm{~mm}$ thick solid aluminium plate with a manufacturer specified precision of $\pm 0.5 \mathrm{~mm}$. The nominal mechanical properties of the aluminium alloy with the designation 5083-O H111 are given in Table 3. It was found that the water-cut process produced an undesirably high surface roughness resembling burr marks on the cut surfaces transversely aligned to the beam axis. As pointed out by Begic-Hajdarevic et al. [29], the surface roughness across the beam width was lower on the side facing the jet nozzle. The cut surface was left untreated with a maximum measured average surface roughness parameter of approximately $R a=12 \mu \mathrm{m}$.

The significant impact of surface roughness on the fatigue life of metal specimens was widely studied e.g. [30, $31]$. In the presented case a $50 \%$ endurance limit reduction was grossly estimated according to the methodology described in $[32,33]$ and used as input to the optimization algorithm. It needs to be underlined that the assumptions taken to estimate the endurance limit reduction were based on relevant literature sources related to specimens manufactured by means of waterjet machining. In fact, the chosen reduction affected the expected fatigue life of the specimens, but did not have an impact on the optimized geometry, which was the outcome of the design algorithm. 
Fig. 8 Underformed beam shape (solid grey) superimposed with the deflected state in mode 1 (solid green); the beam root master node was fully restrained, while a point mass and a sinusoidal force were applied at the beam tip master node. The adopted 4-node bi-linear plane stress quadrilateral elements are shown in the beam root detail
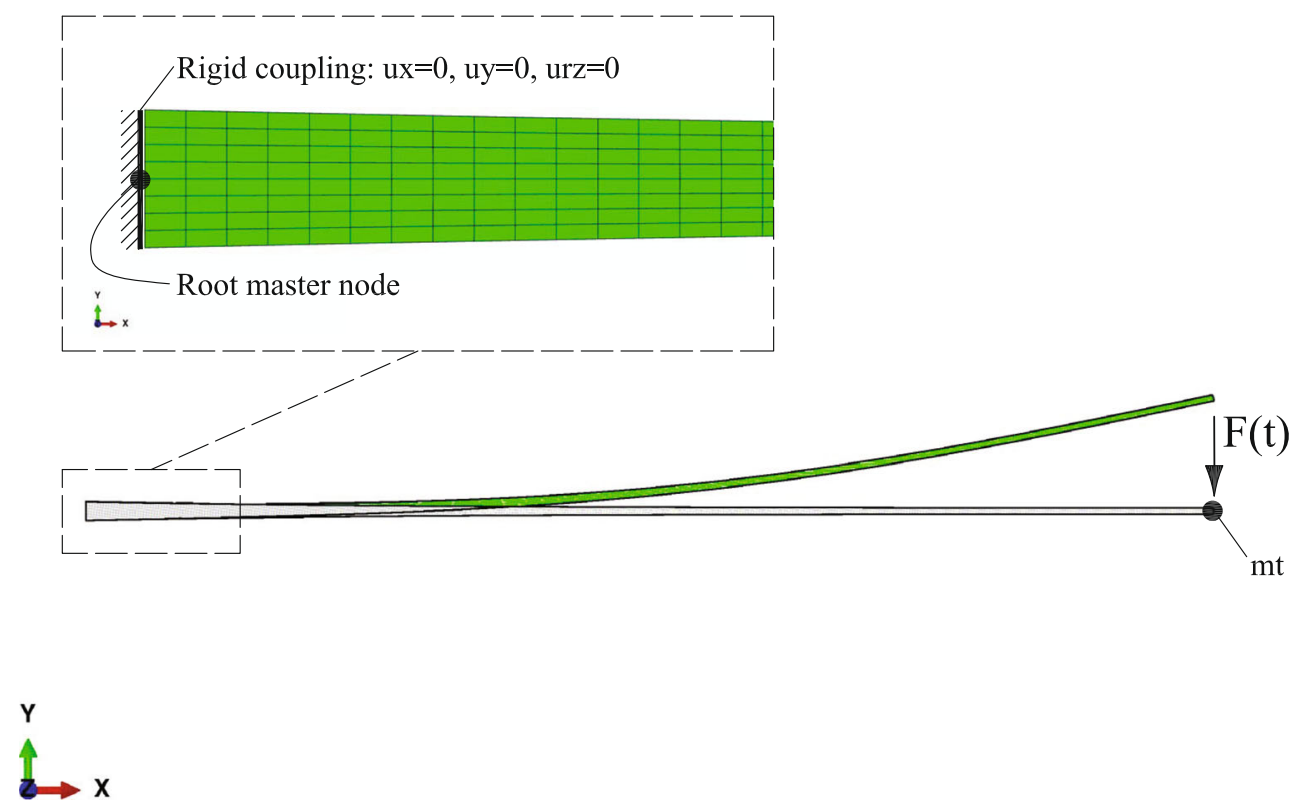

Figure 10 shows the general test setup with one as machined sub-component readily installed. The subcomponent was excited at its first eigenfrequency by a rotating mass exciter mounted at $\mathrm{z}=2000 \mathrm{~mm}$ using a clamped connection, as shown in Fig. 11(a). The rotating mass exciter consisted of a Nema 17 step motor working at a rate voltage of $3.4 \mathrm{~V}$ and a peak current of $2.38 \mathrm{~A}$ with 128 micro-steps. An eccentric mass weighting $58 \mathrm{~g}$ made of brass was connected to the shaft of the motor at a nominal eccentricity of $92 \mathrm{~mm}$ using an M5 threaded pin. The eccentricity measured between the hub and the centre of the eccentric mass was manually adjusted until the desired steady state target displacement was met. The total mass of the entire exciter assembly was $650 \mathrm{~g}$. The tuning mass shown in Fig. 11(b) was made from a solid steel block which was mounted underneath the exciter chassis.

\section{Measurement and control system}

The exciter was controlled by the step motor driver $D M 420 A$, which was connected to the portable reconfigurable I/O (RIO) National Instrument myRIO-1900 running
Fig. 9 (a) Comparison between the sub-component optimized geometry $(L=2000 \mathrm{~mm})$ and the manufactured beam presenting constant height extensions at the clamped connection $(L=310 \mathrm{~mm})$ and at the beam tip $(L=50 \mathrm{~mm})$, (b) sub-component testing setup. Detail A represents the two carbon steel plates forming the test rig, whereas detail B displays the exciter and the tuning mass as mounted on their aluminium support at the beam tip

a)

$\begin{array}{lll}2000 & 2360 & x, 50\end{array}$

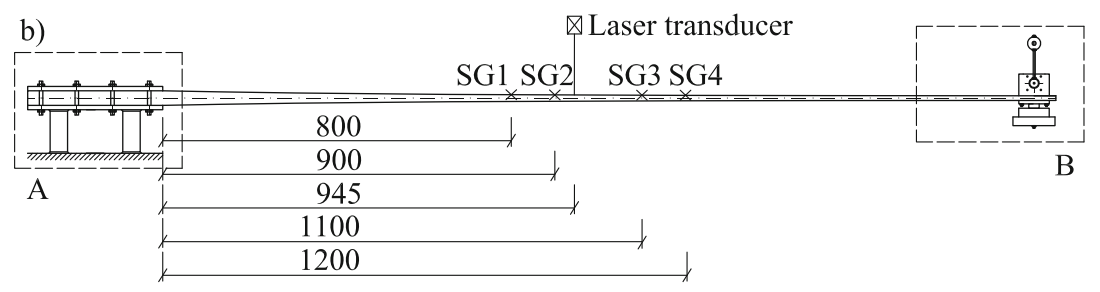

DETAIL A

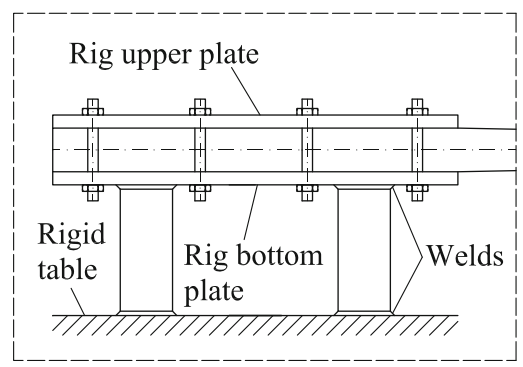

DETAIL B

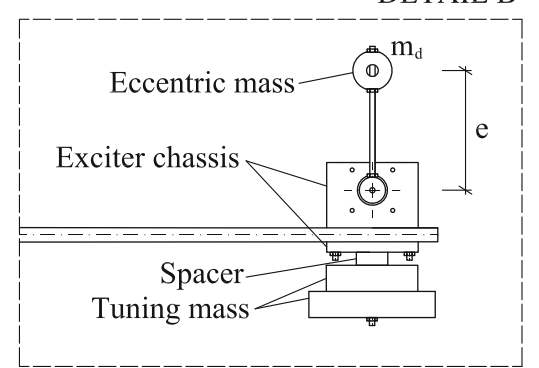




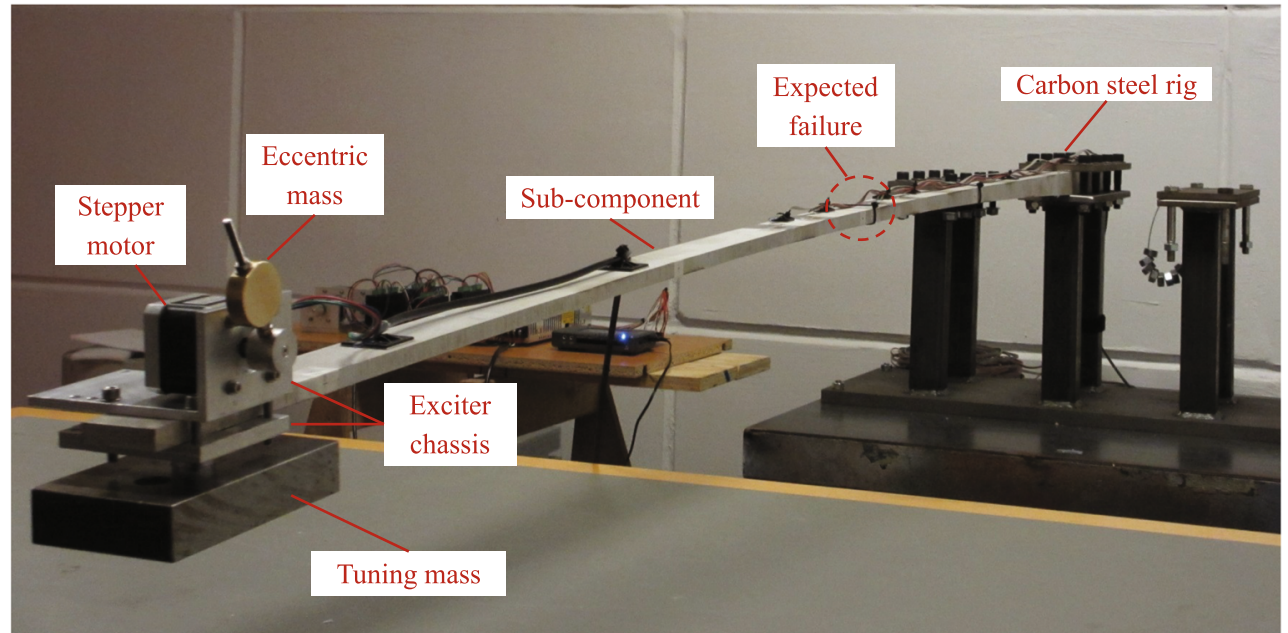

Fig. 10 Aluminium sub-component clamped to a rigid steel rig, which can accommodate three specimens simultaneously; electrical strain gauges used to measure strain distribution along the expected failure area at $\mathrm{z}=1000 \mathrm{~mm}$; rotating mass exciter mounted at the tip with tuning mass bolted to the exciter chassis below

on LabVIEW ${ }^{\odot}$ [34]. The controller was primarily used to set the correct rotational speed. Additionally, it allowed for monitoring the number of load cycles and recording the beam deflection.

The latter was measured contact-less by means of a Micro-Epsilon infrared laser sensor, the optoNCDT 1302, suitable for a $200 \mathrm{~mm}$ measurement range with a measurement precision of $\pm 0.1 \mathrm{~mm}$. Since the tip deflection exceeded the measurement range, the laser sensor was placed at $z=945 \mathrm{~mm}$.

Longitudinal strains were measured at four points symmetrically located on either side of the expected failure area using surface-adhered electrical resistance strain gauges at the longitudinal positions $z=800 \mathrm{~mm}, z=$ $900 \mathrm{~mm}, z=1100 \mathrm{~mm}$ and $z=1200 \mathrm{~mm}$.

\section{Test procedure}

Three identical sub-components were instrumented and tested consistently according to a stipulated procedure. Prior to fatigue testing, a free oscillation test was carried out to determine the natural frequency of the fully instrumented sub-component, including exciter and tuning mass. For this purpose, the beam tip was instantaneously released from a statically deflected position. The damped eigenfrequency was obtained by the inverse of the natural period $f=$ $1 / T$ measured between two adjacent peaks $y_{t i}$ and $y_{t i+1}$ of the unforced system response, where the first few cycles were disregarded. The logarithmic decrement $\Delta$ associated with the first modal shape was computed by the average of equation (30), where the damping coefficient was

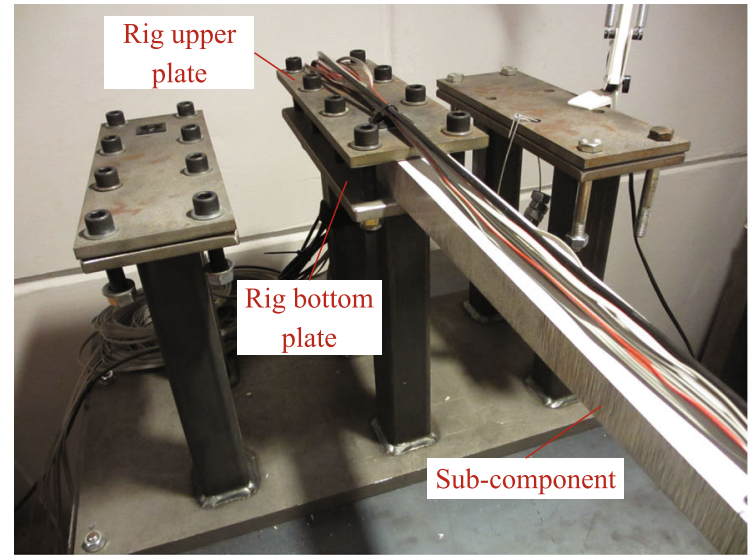

(a)

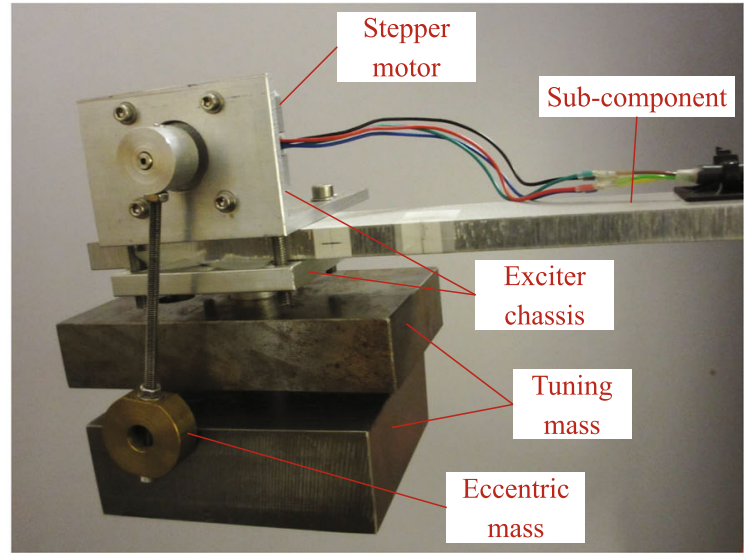

(b)

Fig. 11 (a) Detail of the carbon steel rig used to clamp the sub-component during cyclic excitation, (b) Detail of the excitation system composed of the eccentric mass driven by the stepper motor accommodated on a tailor-made aluminium support and the tuning mass mounted on the bottom beam side 
eventually obtained by equation (31), according to Petersen [35].

$$
\begin{aligned}
& \Delta=\ln \frac{y_{t i}}{y_{t i+1}} \\
& \zeta=\frac{\Delta / 2 \pi}{\sqrt{1+(\Delta / 2 \pi)^{2}}}
\end{aligned}
$$

For the fatigue test, the rotational speed of the step motor was linearly ramped up until the measured natural frequency was reached and a steady state response at the desired displacement and strain amplitudes was achieved. The fatigue test was then conducted until fatigue failure occurred, upon which the exciter was stopped.

\section{Post processing}

During the fatigue test it was necessary for the maximum stress amplitude to exceed the endurance limit in order to decrease $N_{e q}$ to less than $1 \times 10^{7}$ cycles, therefore complying with the optimiser constraint. Since for the adopted aluminium alloy the endurance limit $\sigma_{e}$ is higher than the proof strength $\sigma_{0.2 \%}$, as shown in Table 3, a plastic deformation was inevitably induced during the transient phase. The transient strain amplitude eventually stabilised after a few minutes in the steady state phase. Work hardening of the material caused a quasi-elastic response of all subsequent steady state cycles along the linear stress strain path shown in Fig. 12(a). The maximum stress $\sigma_{\max }$ at maximum steady strain $\epsilon_{\max }$ was obtained by numerically solving the RambergOsgood law given by equation (32), as suggested by Skelton et al. [36].

$\epsilon_{\max }=\frac{\sigma_{\max }}{E}+0.002\left(\frac{\sigma_{\max }}{\sigma_{0.2}}\right)^{n_{R O}}$

where the exponent was set to $n_{R O}=21$, which is a typical value for an 5083-O aluminium alloy plate at room temperature [37].

The plastic strain offset $\epsilon_{p}$ shown in Fig. 12(a) can be calculated by equation (33). The corrected stress history was consequently obtained by the measured strain data and equation (34) using a moving average filter with a time window of $600 \mathrm{~s}$.

$$
\begin{aligned}
\epsilon_{p} & =\epsilon_{\text {max }}-\frac{\sigma_{\text {max }}}{E} \\
\sigma(t) & =\left(\epsilon(t)-\epsilon_{p}\right) E
\end{aligned}
$$

Typically, incipient fatigue failure provoked an increase in the stress amplitude as depicted in Fig. 12(b), which was taken as a reference to determine the event of fatigue failure. The latter was indicated as the instance in time at which the maximum stress exceeded a threshold of $1 \%$ of the average steady state $\sigma_{\max }$. The abrupt increase of the strain amplitudes occurring before sudden death failure is typical for metallic materials. Stress data from the initial transient was disregarded in order to analyse the constant amplitude stress history up to the identified fatigue failure.

The rainflow counting algorithm developed by Nieslony [38] available in Matlab $^{\circledR}$ [21] was subsequently used to extract stress mean $\sigma_{m}$, stress amplitude $\sigma_{a}$ and number

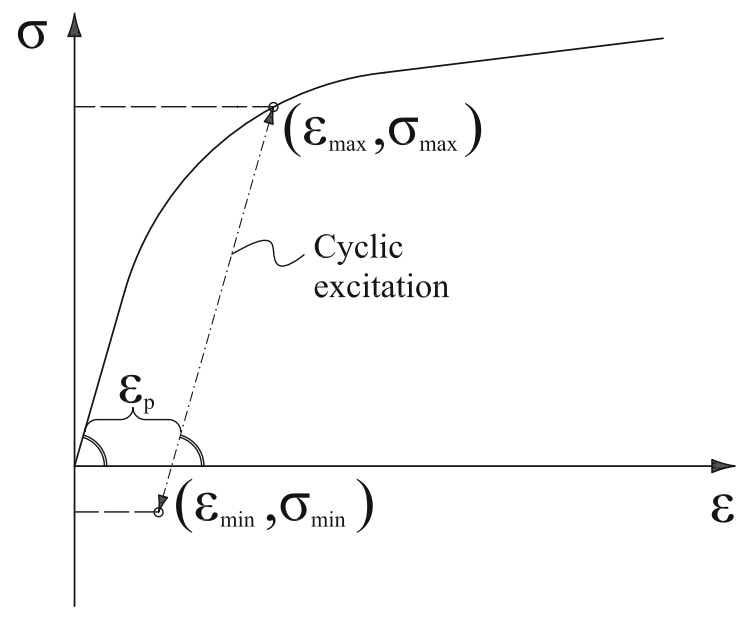

(a)

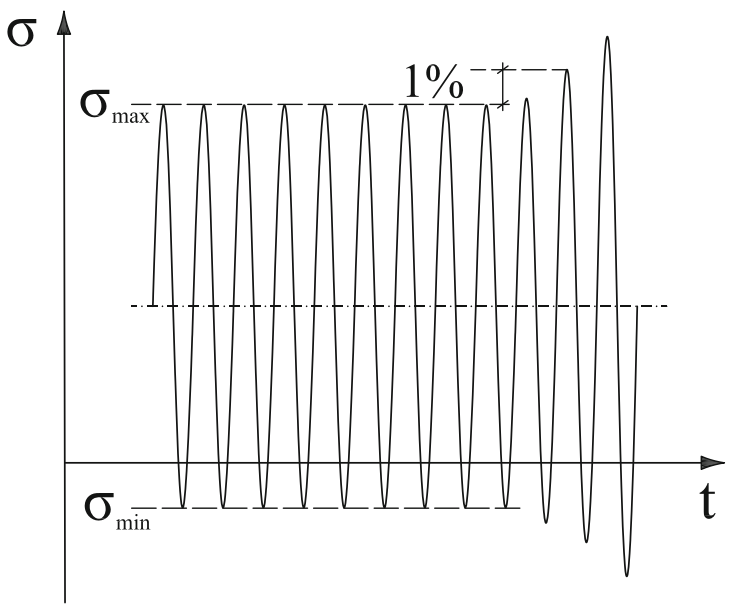

(b)

Fig. 12 (a) Ramberg-Osgood curve defining the stress-strain relation for ductile materials such as aluminium; the linear elastic path followed during the fatigue cyclic excitation (dash-dotted line) and the induced plastic deformation $\epsilon_{p}$ are indicated. (b) Experimental stress time history with indication of the $1 \%$ maximum stress error threshold used to define incipient fatigue failure 


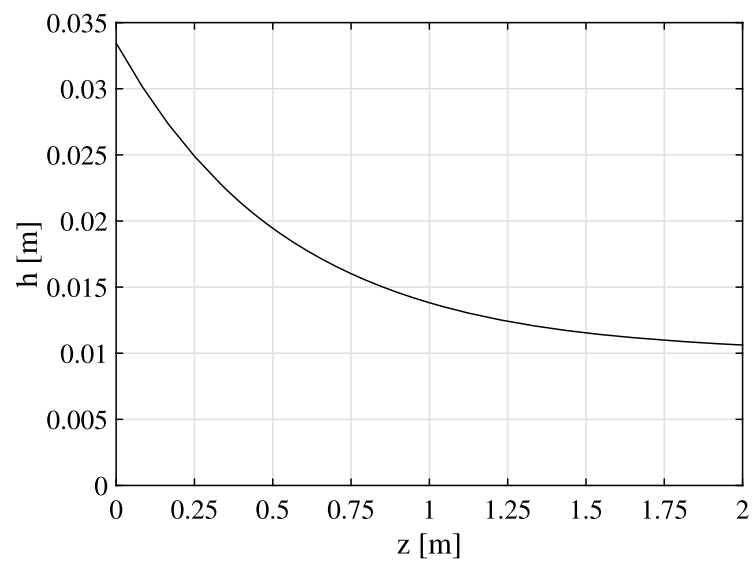

(a)

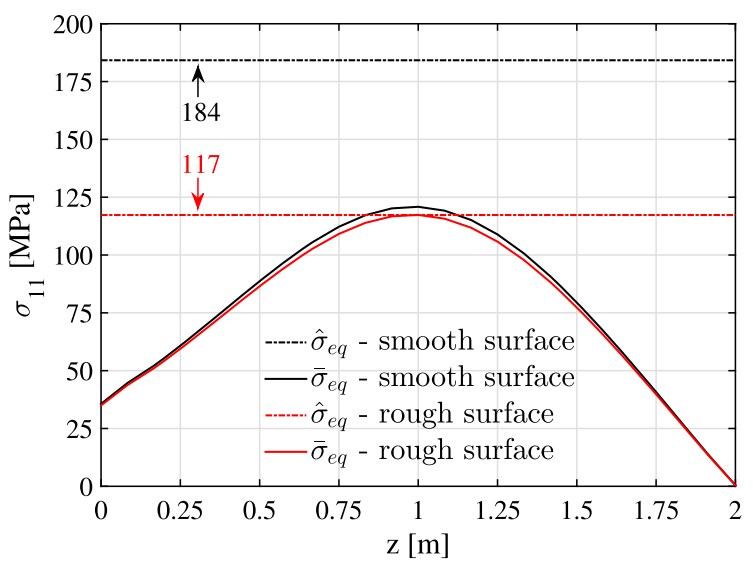

(b)

Fig. 13 (a) Sub-component beam total height obtained as a result of the optimization algorithm, (b) Distribution of the beam characteristic stresses as a function of the beam longitudinal coordinate $z$ : the material fatigue equivalent stress $\hat{\sigma}_{e q}$ and the applied dynamic equivalent stress $\bar{\sigma}_{e q}$ for the presented solutions for smooth surface (in black) and rough surface (in red)

of cycles $N_{f}$ at incipient failure in the four strain gauge locations.

Mean stress and stress amplitude distributions were interpolated along the longitudinal coordinate by using a second order polynomial, which was considered to provide a good approximation of both stress distributions in the sub-component strain gauge instrumented portion. Equation (17) was finally used to obtain the equivalent dynamic stress distribution.

\section{Results}

\section{Optimization Results}

Figure 13(a) depicts the optimized cross section height as a function of the longitudinal coordinate. Figure 13(b) shows the equivalent principal stress distributions as a function of the longitudinal coordinate. As can be seen from Fig. 13(b), the dynamic stress amplitude reaches its maximum at the beam mid-span, while it remains significantly lower at the clamped connection and approaches zero at the beam tip.

Two different solutions are presented, the first of which was obtained by assuming the theoretical endurance limit value for a smooth surface, while the second by assuming a 50\% reduction of the endurance limit for a rough surface. The latter shows a drop in the evaluated material fatigue strength $\hat{\sigma}_{e q}$ from $184 \mathrm{MPa}$ to $117 \mathrm{MPa}$, equal to the $36 \%$ of the value for smooth surface, as shown in Fig. 13(b). Table 4 reports the optimised design variables for the presented solutions for smooth and rough surface. The latter was carried forward in the experimental campaign.

\section{Semi-analytical and Numerical Results}

The semi-analytical model was validated against the numerical model for the two static load cases: beam selfweight and concentrated tip load. In both cases, as shown in Fig. 14(a) and (b), respectively, the stress components predicted by the semi-analytical model agreed well with the numerical simulations. However, the numerical model shows a significant deviance at the root (see single markers), which was attributed to the difference between the warping restraint posed by the kinematic coupling and the free cross-section rotation underlying beam theory.

Figure 15 compares the first three numerically obtained eigenmodes with the semi-analytical solution given by equation (7). The associated first three numerically obtained eigenfrequencies were $f_{1}=2.088 \mathrm{~Hz}, f_{2}=18.021 \mathrm{~Hz}$ and $f_{3}=50.012 \mathrm{~Hz}$. Figure 16(a) shows the numerically obtained time-history displacement envelope superimposed with the semi-analytical solution for a damping ratio equal to $2.0 \times 10^{-3}$. Figure 16 (b) compares the experimental time-history displacement envelope with the semi-analytical solution for an experimentally obtained damping ratio of $7.6 \times 10^{-4}$. The experimental surface mean strain and strain

Table 4 Optimal parameters of the design variables and resonance frequency for the presented solutions for smooth and rough surface

\begin{tabular}{lll}
\hline & Smooth surface & Rough surface \\
\hline$h_{0}$ & $33.45 \mathrm{~mm}$ & $33.45 \mathrm{~mm}$ \\
$\gamma$ & 1.815 & 1.815 \\
$m_{t}$ & $6.0 \mathrm{~kg}$ & $5.6 \mathrm{~kg}$ \\
$y_{n}$ & $250 \mathrm{~mm}$ & $246 \mathrm{~mm}$ \\
$f_{1}$ & $1.42 \mathrm{~Hz}$ & $1.46 \mathrm{~Hz}$ \\
\hline
\end{tabular}




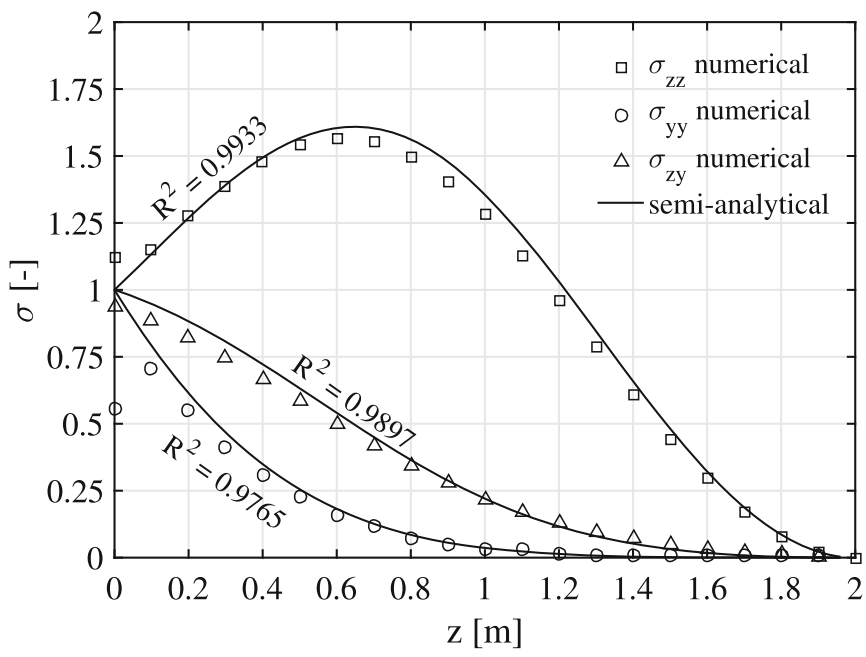

(a)

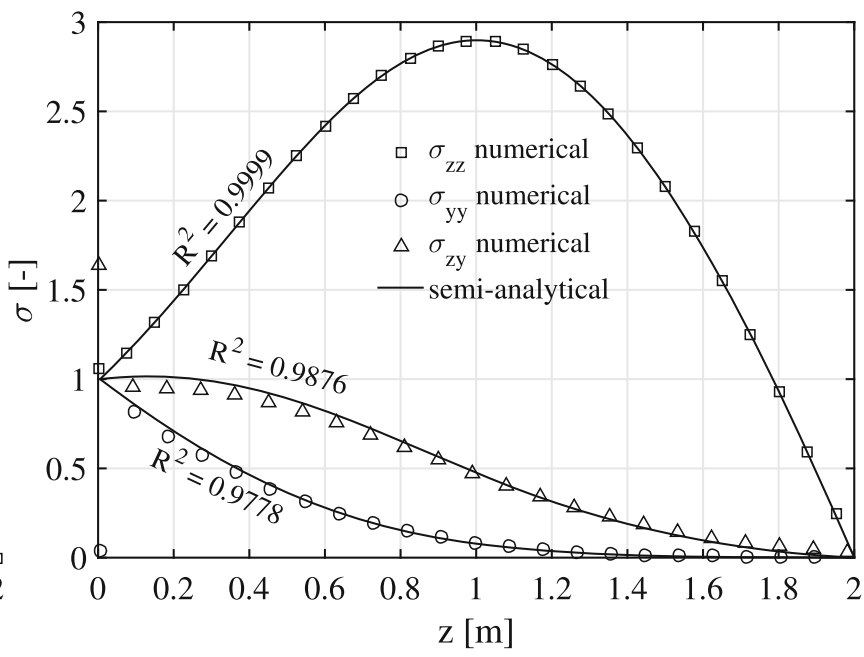

(b)

Fig. 14 (a) Comparison between the three stress components normalized against the semi-analytical value at $z=0$ for the self-weight static load case, (b) Comparison between the three stress components normalized against the semi-analytical value at $z=0$ for the static tip load case

amplitude were compared to the semi-analytical solution, in Fig. 17(a) and(b).

\section{Experimental Results}

Every test displayed the occurrence of a single discrete crack initiating in the top surface and propagating through the thickness at the designated failure area, as shown in Fig. 18. On the basis of the strain measurements, the equivalent stress distribution was calculated according to the procedure presented in Section 2 and is compared in Fig. 20 for the three tested sub-components.

Table 5 reports the most relevant parameters with respect to the three tests, i.e., the excitation frequency, the longitudinal coordinate of the observed crack, the number of

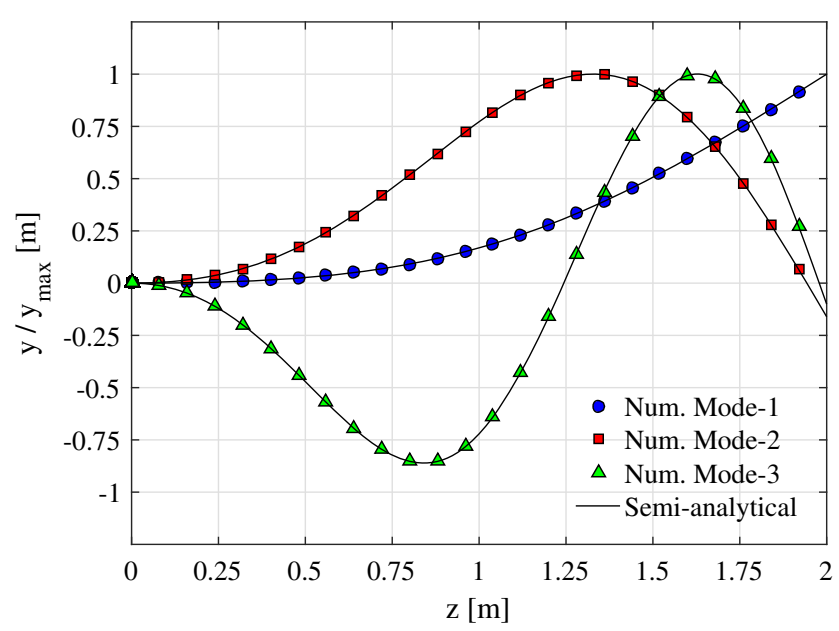

Fig. 15 Numerically and semi-analytically obtained mode shapes for the first three eigenfrequencies cycles at incipient failure and the fatigue R-ratio. Both the number of cycles and the R-ratio are obtained as the average between the four measurement points.

The fracture surfaces of one of the sub-components are presented in Fig. 19.

Figure 20 shows that sub-component no. 2 failed at the designated cross section, where sub-components no. 1 and no. 3 failed $120 \mathrm{~mm}$ and $150 \mathrm{~mm}$ closer to the root. Comparison of the equivalent stress amplitude distributions shows that the peaks of sub-components no. 1 and no. 2 were slightly shifted towards the root.

\section{Discussion}

Time-history analysis was conducted semi-analytically and by finite element method. The semi-analytical model was validated against the test results by assuming the experimentally determined damping coefficient equal to $\zeta=7.6 \times 10^{-4}$. On the other hand, the validation against the numerical model was conducted by assuming a damping coefficient equal to $\zeta=2.0 \times 10^{-3}$. It was noticed that, for damping coefficient values below this threshold, the numerical model overestimated the displacement amplitude with an error increasing for decreasing damping coefficients. The chosen value was the lowest possible preventing model instability. The latter appeared to be related to numerical damping, as discussed in the Abaqus ${ }^{\odot}$ Analysis User's Manual [27, Vol. II, section 6.3.2]. Moreover, different numerical parameters associated with the Hilber-Hughes-Taylor operator were tested, and the observed solver dependency of the solution for damping coefficient values below the presented threshold pointed 


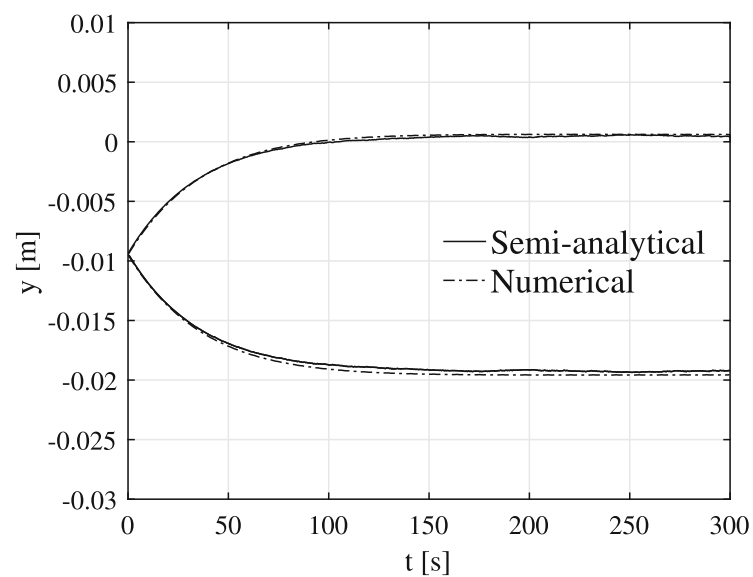

(a)

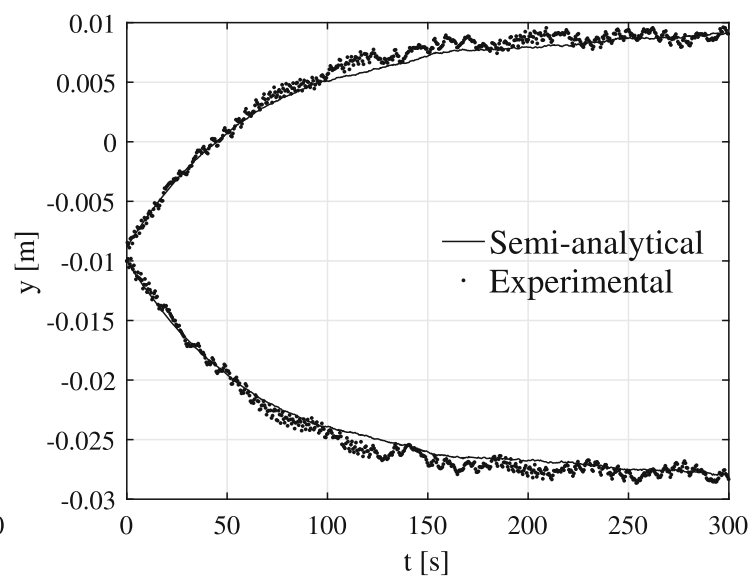

(b)

Fig. 16 (a) Semi-analytical and numerical displacement envelopes under resonance excitation for $\zeta=2.0 \times 10^{-3}$ at a longitudinal position $z=9.45 \times 10^{2} \mathrm{~mm}$, (b) Semi-analytical and experimental displacement envelopes under resonance excitation for $\zeta=7.6 \times 10^{-4}$ at a longitudinal position $z=9.45 \times 10^{2} \mathrm{~mm}$

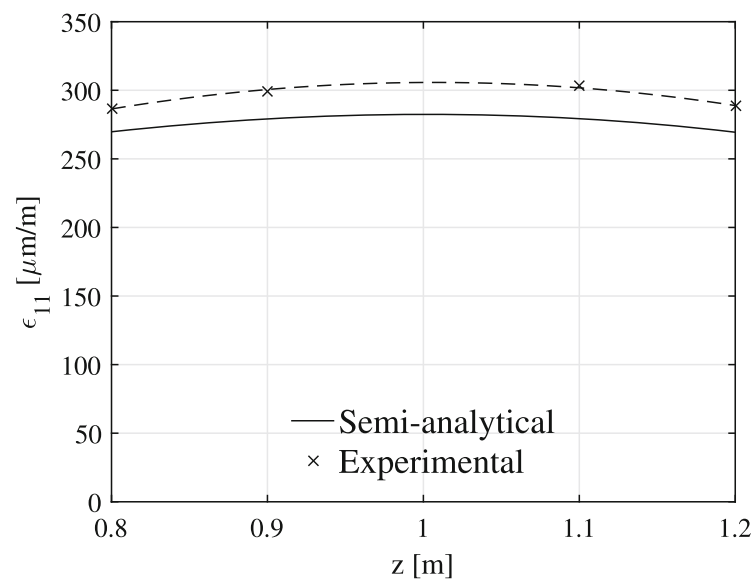

(a)

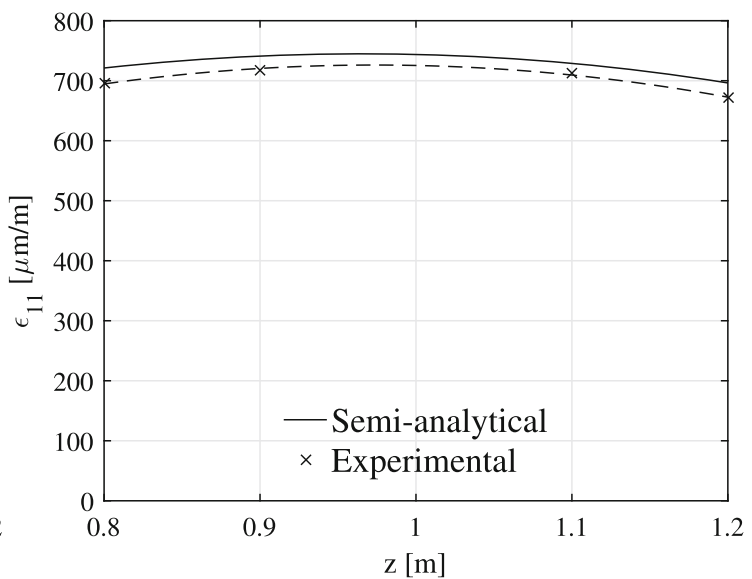

(b)

Fig. 17 (a) Semi-analytical and experimental mean strain distribution in vicinity of the gauge section under resonance excitation, (b) Semianalytical and experimental dynamic strain amplitude distribution at the gauge section (i.e., designated failure region) under resonance excitation with strain gauge positions indicated by cross markers

Fig. 18 Fatigue cracks in the tensile surface of $(\mathbf{a})$

Sub-component no. 1 at $120 \mathrm{~mm}$ offset, (b) Sub-component no. 2 at $8 \mathrm{~mm}$ offset, and (c) Sub-component no. 3 at $150 \mathrm{~mm}$ offset, with cracks highlighted by two red marks

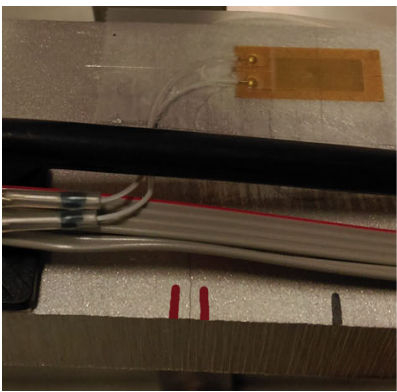

(a)

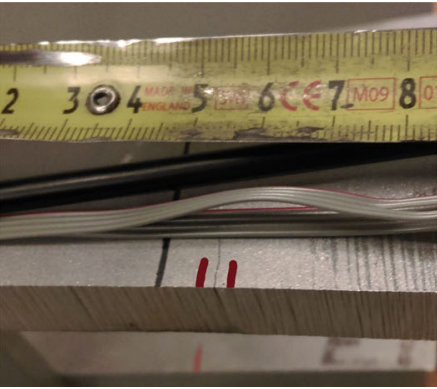

(b)

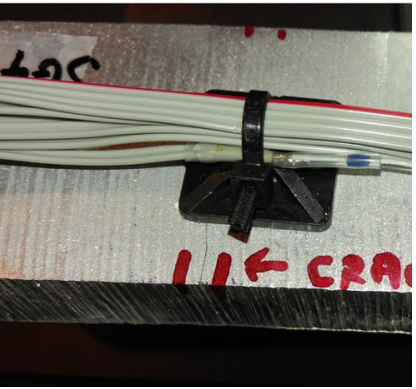

(c) 
Table 5 Experimental results for every tested sub-component, resonance excitation frequency $f_{1}$, fatigue failure longitudinal location $z_{f}$, number of cycles at incipient failure $N_{f}$ and fatigue R-ratio $R$

\begin{tabular}{lllll}
\hline Sub-component no. & $f_{1}[\mathrm{~Hz}]$ & $z_{f}[\mathrm{~m}]$ & $N_{f}[-]$ & $R[-]$ \\
\hline 1 & 1.508 & $8.800 \mathrm{e}+2$ & $3.204 \mathrm{e}+5$ & -0.384 \\
2 & 1.453 & $1.008 \mathrm{e}+3$ & $1.396 \mathrm{e}+5$ & -0.260 \\
3 & 1.443 & $8.500 \mathrm{e}+2$ & $3.398 \mathrm{e}+5$ & -0.280 \\
\hline
\end{tabular}

towards a software issue rather than a weakness of the dynamic model. However, the different choice of the damping coefficient did not affect the validity of the model validation.

The observed fatigue crack in all the sub-components was not a through-thickness crack, since the local stiffness variation due to the propagating crack during the test altered the beam modal response and gradually shifted the resonance frequency away from the test frequency. It was therefore not possible to conduct the tests until complete failure was reached. The fatigue crack was then mechanically opened by applying a static bending moment. Fig. 19 shows the fatigued burnished surface region, clearly separated from the statically failed coarse granular region. The deviation of the stress peaks between different tests depicted in Fig. 20 can be attributed to manufacturing tolerances and experimental uncertainties, which impeded the reproducibility of the dynamic loading conditions. Table 5 shows that every sub-component exhibited a different resonance frequency due to variations of geometry and installation of the sub-component and its equipment. In addition, the damping behaviour of the sub-components was at variance to one another. In order to match the desired strain amplitude, the excitation frequency needed to be individually adjusted leading to excitations slightly remote from the natural frequency. A controller based excitation force is recommended for a more consistent and accurate match of the desired strain amplitude.

The fatigue life obtained from the test campaign was lower than the estimations. The experimentally applied dynamic equivalent stress $\bar{\sigma}_{e q}$, calculated at the sub-component mid-span, appeared to be approximately $10 \%$ lower than the estimated value, where the discrepancy was attributed to non-linear effects related to the RambergOsgood curve and the material plastic deformation, which were neglected within the analytical formulation used for the optimization algorithm. Additionally, the experimentally obtained number of cycles at fatigue failure, presented in Table 5 for the three tested sub-components, was found to be lower than $N_{e q}=4 \times 10^{5}$, used as input for the optimization algorithm. The main reason for this deviation is deemed to be associated with a reduction of the fatigue properties as pointed out in Section 2 due to the effect of surface roughness in conjunction with uncertainties related to the calculative consideration of the latter. This hypothesis is corroborated by the fact that all cracks initiated on the side with the higher surface roughness. The deviance between the equivalent stress peaks and failure locations shown in Fig. 20 can be caused by critical surface notches (burr marks) prevailing remotely from the dynamic stress peak.

The increased complexity of the sub-components compared to small scale tests increases the likelihood of flaws and imperfections being present. In other words, a deviation of the failure location from the designated cross section can be expected. Especially in the case of fibre-reinforced composite materials, failure will not be at a specific point but rather spread out in the form of a failure zone due to gradual material degradation.

However, Fig. 13(b) shows that the proposed method is rather robust and insensitive to variations of fatigue parameters. That is to say, a reduction of the fatigue parameters, as long as these variations are fairly uniformly distributed, causes a down shift of the horizontal line in Fig. 13(b) where boundary failure remains prohibited.

This paper aims at demonstrating how lengthwise geometry variations, e.g. taper, can be used to trigger specific failure modes and to simultaneously obtain gauge sections remote from the boundaries, independently from the material used. This method is based on the hypothesis that high-cycle fatigue failure occurs at the location of the

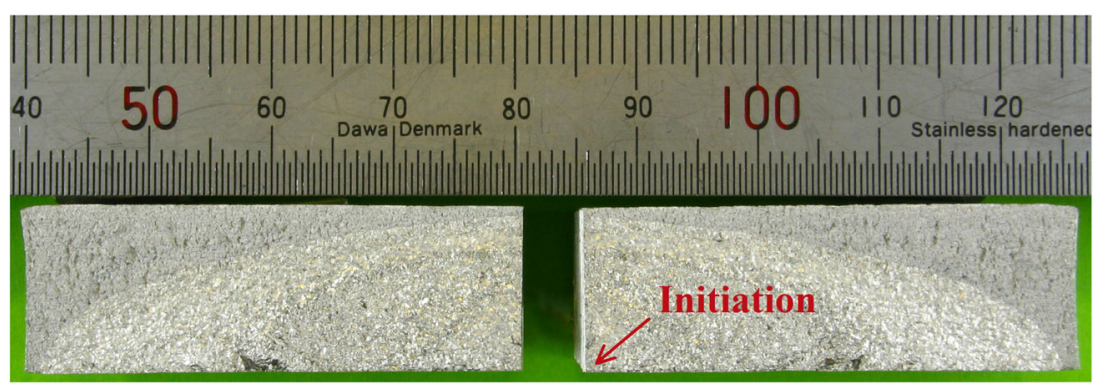

Fig. 19 In the fractograph a smooth distinct burnished area borders a coarse granular area. The burnished area originates from mutual abrasion of the crack faces during cyclic loading whereas the granular area is attributed to micro void formation during fast fracture. The absence of beach marks is typical for constant amplitude situations in conjunction with the aluminium alloy used 


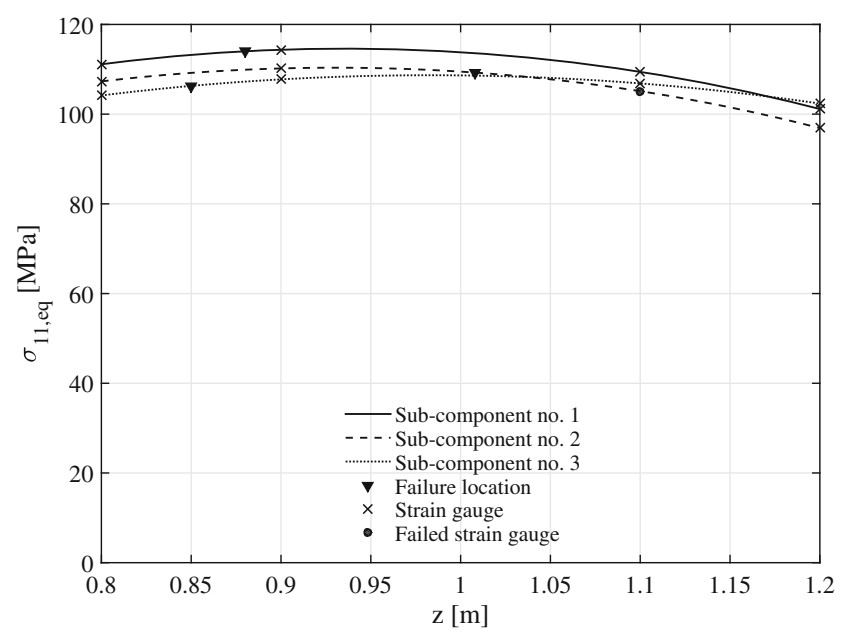

Fig. 20 Equivalent principal stress amplitude distribution calculated from strain measurements shown as continuous lines at the designated failure region for the three tested sub-components, with strain gauge positions indicated by cross markers (a circular marker is used to indicate the position of a failed strain gauge, where the measurements were interpolated). For every sub-component, fatigue-induced cracks were observed at the indicated failure locations (triangular markers)

fatigue stress peak along the sub-component. Although the failure mechanisms for aluminium and composite materials are different, the authors' intent was to demonstrate how fatigue failure was indeed obtained at the designated gauge section. In fact, the presented method can be used to maximize a specific stress component, which can then trigger a specific failure mode, accordingly to the chosen material. In the case presented as proof of concept, the tapered geometry was optimized to provoke failure due to bending in the extreme fibres. However, if a different failure mode, such as shear failure, were in the research scope, a different geometry would be obtained.

This methodology can be applied to tapered fibrereinforced composite beams presenting a box girder or an I-beam geometry similar to the load carrying part of a wind turbine blade, where the flange layup and the web geometry are designed by means of the proposed algorithm. For applications to composite sub-components, a progressive failure model would need to be included in the design algorithm to account for the material anisotropy and different failure modes such as inter fibre failure in the transverse and/or in-plane shear direction. Additionally, if adhesive is used, a cohesive failure model should be included.

\section{Conclusion}

The proposed concept for a novel sub-component testing technique was experimentally proven inasmuch all subcomponents failed in vicinity of the designated location remote from the boundaries. Experimental data showed that the fatigue life was lowered to a large extent by the high surface roughness. Moreover, material non-linearity due to plastic deformation added to the complexity owing to the proximity of both endurance limit and yield strength in the aluminium alloy used. However, this does not negate the fact that the designated failure location at mid-span remained largely unaffected by average deviations of material fatigue properties.

It must be stressed that the proposed method does not rely on resonance excitation, but can straight forwardly be modified for non-resonant forced loading conditions, e.g., those induced by actuators or linear motors. It can be concluded that the proposed method is generally applicable to cantilever beam-type structures. The method lends itself especially to sub-components with shapes that already resemble tapered beams whose material behaviour is predominantly linear elastic, as is the case for load carrying box girders of wind turbine blades.

Acknowledgements The work presented in this paper has partly received funding from the European Community's Seventh Framework Programmed under funding scheme: Combination of CP \& CSA with grant agreement No. 609795 (IRPWIND). The support is gratefully acknowledged. The authors are grateful for the support of Giorgio Demurtas and Claus Brian Munk Pedersen from DTU Wind Energy (TEM) in the field of measurement and control. The authors additionally appreciate the support of Philipp Haselbach, Kim Branner and Alexander Verbart from DTU Wind Energy (SAC).

\section{References}

1. Weibull W (1939) A statistical theory of the strength of materials. Ingeniörsvetenskapsakademiens Handlingar

2. Bazant ZP, Planas J (1998) Fracture and size effect in concrete and other quasibrittle materials. CRC Press, Boca Raton

3. Wisnom MR (1999) Size effects in the testing of fibre-composite materials. Compos Sci Technol 59:1937-1957

4. Eder MA, Bitsche RD (2015) Fracture analysis of adhesive joints in wind turbine blades. Wind Energy 18:1007-1022

5. Eder MA (2011) Inelastic behaviour of hybrid steel/concrete column-to-flat slab assemblages, Ph.D. thesis, Imperial College London

6. Høgh J, Waldbøjrn J, Wittrup-Schmidt J, Stang H, Berggreen C (2015) Quasi-static single-component hybrid simulation of a composite structure with multi-axis control. Strain 51(6):459-473

7. Branner K, Berring P, Haselbach PU (2016) Subcomponent testing of trailing edge panels in wind turbine blades. In: Proceedings of 17th European conference on composite materials

8. Mandell JF, Combs DW, Samborsky DD (1995) Fatigue of Fiberglass Beam Substructures. Wind Energy 16:99-106

9. Mandell JF, Samborsky DD, Combs DW, Scott ME, Cairns DS (1998) Fatigue of composite material beam elements representative of wind turbine blade substructure. Tech. rep., National Renewable Energy Laboratory

10. Zarouchas DS, Makris AA, Sayer F, Van Hemelrijck D, Van Wingerde AM (2012) Investigations on the mechanical behavior of a wind rotor blade subcomponent. Compos Part B 43(2):647654 
11. Asl ME, Niezrecki C, Sherwood J, Avitabile P (2014) Application of structural similitude theory in subcomponent testing of wind turbine blades. In: Conference: proceedings of the american society for composites - 29th technical conference

12. Asl ME, Niezrecki C, Sherwood J, Avitabile P (2016) Design of scaled-down composite I-beams for dynamic characterization in subcomponent testing of a wind turbine blade. Shock \& Vibration, Aircraft/Aerospace, Energy Harvesting, Acoustics \& Optics 9:197-209

13. Asl ME, Niezrecki C, Sherwood J, Avitabile P (2017) Scaled composite I-beams for subcomponent testing of wind turbine blades: an experimental study. In: Conference proceedings of the society for experimental mechanics series, vol 6, pp 71-78

14. Simitses GJ, Rezaeepazhand J (1993) Structural similitude for laminated structures. Compos Eng 3:751-765

15. Sayer F, Antoniou A, van Wingerde A (2012) Investigation of structural bond lines in wind turbine blades by sub-component tests. Int J Adhes Adhes 37:129-135

16. Fernandez G, Usabiaga H, Vandepitte D (2017) Subcomponent development for sandwich composite wind turbine blade bonded joints analysis. Compos Struct 180:41-62

17. Fine ME (1980) Fatigue resistance of metals. Metall Trans A 11:365-379

18. Mang H, Hofstetter G (2000) Festigkeitslehre. Springer, Wien New York

19. Atkinson KE (1989) An introduction to numerical analysis, 2nd edn. Wiley, New York

20. Liu M, Gorman DG (1995) Formulation of Rayleigh damping and its extensions. Comput Struct 57:277-285

21. The MathWorks, Inc., Natick, Massachusetts, United States, MATLAB and Statistics Toolbox Release 2015a (2014)

22. Ashino R, Nagase M, Vaillancourt R (2000) Behind and Beyond the MATLAB ODE Suite. Comput Math Appl 40:491-512

23. Park KC (1977) Practical aspects of numerical time integration. Comput Struct 7(3):343-353
24. Bennati S, Bertolini P, Taglialegne L, Valvo PS (2016) On shear stresses in tapered beams. In: GIMC-GMA 2016, XXI Convegno nazionale di Meccanica Computazionale e VIII Riunione Gruppo Materiali AIMETA

25. Basquin O (1910) The exponential law of endurance tests. Proc ASTM 10:625-630

26. Kim HC, Ebert LJ (1979) Fatigue life-limiting parameters in fibreglass composites. J Mater Sci 14:2616-2624

27. (2014) Dassault Systèmes, Abaqus Analysis User's Manual

28. Hilber HM, Hughes TJR, Taylor RL (1977) Improved numerical dissipation for time integration algorithms in structural dynamics. Earthq Eng Struct Dyn 5:283-292

29. Begic-hajdarevic D, Cekic A, Mehmedovic M, Djelmic A (2015) Experimental study on surface roughness in abrasive water jet. Procedia Eng 100:394-399

30. Bayoumi MR, Abdellatif AK (1995) Effect of surface finish on fatigue strength. Eng Fract Mech 51(5):861-870

31. Suraratchai M, Limido J, Mabru C, Chieragatti R (2008) Modelling the influence of machined surface roughness on the fatigue life of aluminium alloy. Int J Fatigue J 30:2119-2126

32. IIT Kharagpur Lectures, Version 2 ME, Module 3 Design for Strenght, Lesson 3 Design for dynamic loading (2000)

33. Arola D, Williams CL (2002) Estimating the fatigue stress concentration factor of machined surfaces. Int J Fatigue 24:923-930

34. National Instruments, Austin, Texas, United States, LabVIEW v15 (2015)

35. Petersen C (2000) Dynamik der Baukonstruktionen, Friedr, Vieweg \& Sohn Verlagsgesellschaft $\mathrm{mbH}$

36. Skelton RP, Maier HJ, Christ H (1997) The Bauschinger effect, Masing model and the Ramberg - Osgood relation for cyclic deformation in metals. Mater Sci Eng 238:377-390

37. Military handbook, metallic materials and elements for aerospace vehicle structures (1998)

38. Nieslony A Rainflow counting algorithm - very fast rainflow cycle counting for MATLAB. http://www.mathworks.com/ matlabcentral/fileexchange 